\title{
Aligned Magnetic Field and Radiation Effects on Biomagnetic Fluid over an Unsteady Stretching Sheet with Various Slip Conditions
}

\author{
Anik Gomes ${ }^{1}$, Jahangir Alam ${ }^{1}$, Ghulam Murtaza ${ }^{1}$, Tahmina Sultana ${ }^{2}$, Efstratios E. Tzirtzilakis ${ }^{3, *(D)}$ \\ and Mohammad Ferdows 4 \\ 1 Department of Mathematics, Comilla University, Comilla 3506, Bangladesh; \\ thomasanikgomes@gmail.com (A.G.); jahangircu1994@gmail.com (J.A.); limonn@yahoo.com (G.M.) \\ 2 Department of Science and Humanities, Military Institute of Science and Technology, \\ Dhaka 1216, Bangladesh; tahmina2011@yahoo.com \\ 3 Fluid Mechanics \& Turbomachinery Laboratory, Department of Mechanical Engineering, \\ University of the Peloponnese, 26334 Patras, Greece \\ 4 Research Group of Fluid Flow Modeling and Simulation, Department of Applied Mathematics, \\ University of Dhaka, Dhaka 1000, Bangladesh; ferdows@du.ac.bd \\ * Correspondence: etzirtzilakis@uop.gr
}

check for updates

Citation: Gomes, A.; Alam, J.; Murtaza, G.; Sultana, T.; Tzirtzilakis, E.E.; Ferdows, M. Aligned Magnetic Field and Radiation Effects on Biomagnetic Fluid over an Unsteady Stretching Sheet with Various Slip Conditions. AppliedMath 2021, 1 , 37-62. https://doi.org/10.3390/ appliedmath1010004

Academic Editor: Takayuki Hibi

Received: 27 October 2021

Accepted: 10 December 2021

Published: 14 December 2021

Publisher's Note: MDPI stays neutral with regard to jurisdictional claims in published maps and institutional affiliations.

Copyright: (c) 2021 by the authors. Licensee MDPI, Basel, Switzerland. This article is an open access article distributed under the terms and conditions of the Creative Commons Attribution (CC BY) license (https:/ / creativecommons.org/licenses/by/ $4.0 /)$.

\begin{abstract}
The aim of the present study is to analyze the effects of aligned magnetic field and radiation on biomagnetic fluid flow and heat transfer over an unsteady stretching sheet with various slip conditions. The magnetic field is assumed to be sufficiently strong enough to saturate the ferrofluid, and the variation of magnetization is approximated by a linear function of temperature difference. The governing boundary layer equations with boundary conditions are simplified by suitable transformations. Numerical solution is obtained by using the bvp4c function technique in MATLAB software. The numerical results are derived for the velocity, temperature, the skin friction coefficient, and the rate of heat transfer. The evaluated results are compared with analytical study documented in scientific literature. The present investigation illustrates that the fluid velocity is decreased with the increasing values of radiation parameter, magnetic parameter, and ferromagnetic interaction parameter, though is increased as the Prandtl number, Grashof number, permeable parameter and thermal slip parameter are increased. In this investigation, the suction/injection parameter had a good impact on the skin friction coefficient and the rate of heat transfer.
\end{abstract}

Keywords: biomagnetic fluid; thermal radiation; heat flux; magnetic field; unsteady; stretching sheet; skin friction; rate of heat transfer

\section{Introduction}

During the last few decades, due to its application in several areas in science and engineering, the study of flow and heat transfer over an unsteady stretching sheet has drawn significant attention to researchers. The study of rotating flow and heat transfer has received fervent interest in modern fluid dynamics research, with applications in geophysics, biomedical engineering, medical science, planetary science, thermal insulations, etc.

Biomagnetic Fluid Dynamics (BFD) is the study of the effects of an applied magnetic field on biological fluid flow [1]. The most characteristic biomagnetic fluid is blood. Blood is a suspension of numerous cells such as red blood cells, white blood cells, and platelets in a liquid electrolyte solution called plasma. Plasma contains $7 \%$ of principal proteins and $90 \%$ of water, along with considerable concentration of ions. Blood as a whole is considered as a non-Newtonian fluid predominantly when the characteristic dimension of the flow is nearby the cell dimension. As far as the stretching sheet flows are concerned, Crane [2] computed an exact similarity solution for the boundary layer flow of a Newtonian fluid towards an elastic sheet. The sheet was stretched with the velocity proportional to the 
distance from the origin. Barozzi and Dumas [3] numerically studied the convective heat transfer in blood vessels of the circulatory system. They observed that the rheological behavior of blood does not significantly affect the heat transfer rate in small blood vessels. Pennes [4] studied the effects of blood perfusion and metabolic heat generation in living tissues using a simplified bio-heat transfer model. Although this model bears the potential to describe the effect of blood flow on tissue temperature, it has some considerable short comings. This is because uniform perfusion rate was assumed, and the direction of blood flow was not accounted for. Moreover, in his model, only the stream of venous blood as the fluid stream equilibrated with tissue was considered.

In recent years, the study of the magneto hydrodynamic (MHD) flow of blood through the arteries has gained considerable interest because of its important applications in physiology. Theoretical estimates of blood flow in arteries during the therapeutic procedure of electromagnetic hyperthermia used for cancer treatment were reported by Misra et al. [5]. A few important discussions were also available in that paper. The effects of electromagnetic radiation/ultrasonic radiation on blood flow were studied by other investigations such as those of Inoue et al. [6], Nishimoto et al. [7], Bidin and Nazar [8], Irfan et al. [9], and Ishak [10]. The effect of viscous dissipation and radiation on the unsteady flow of electrically conducting fluid passed over a stretching surface was considered by Brickman [11] and Chand et al. [12]. The variable viscosity and thermal conductivity effects of combined heat and mass transfer in mixed convection over a UHF/UMF wedge in porous media were analyzed by Hassanien et al. [13] and Khan et al. [14]. Moreover, the effects of variable viscosity and thermal conductivity on a thin film flow over a shrinking/stretching sheet were also studied. Pal and Mondal [15] studied the effects of temperature-dependent viscosity and variable thermal conductivity on an MHD, non-Darcy mixed convection diffusion of species over a stretching sheet. The effects of thermal radiation over a stretching sheet under several flow conditions have been also studied by several researchers [16-20].

Furthermore, a study of microploar fluid under the influence of a magnetic field through a stretched curved surface, using the Cattaneo-Christov heat model investigated by Khan et al. [21], had found that, in fluid velocity, the magnetic field parameter plays a significant role. The movement of peristaltic flow of a dusty fluid with elastic properties in a curved configuration was analyzed by Khan et al. [22]. A fully developed model of non-Newtonian fluid through a 2D stretching sheet in the presence of Lorentz force and internal heat was presented by Vijaya et al. [23]. The BFD model [1], which involves both ferrohydrodynamics (FHD) and magnetohydrodynamics (MHD) principles, was utilized for the study of the effect of thermal radiation through a two-dimensional unsteady stretching sheet by Alam et al. [24]. Finally, the impact of MHD on non-Newtonian mass and heat transfer along a curved stretched sheet was numerically studied by Yasim et al. [25].

The aim of the present investigation is to study the flow and heat transfer in a stretching sheet with an angle $\alpha$ to the vertical plane in the presence of a non-uniform source/sink. The mathematical formulation of the effect of the magnetic field is that of BFD, involving both principles of ferrohydrodynamics (FHD) and MHD [1]. The governing partial differential equations have been transformed by similarity transformations into a coupled system of nonlinear ordinary differential equations. The solution was attained by using a MATLAB package. The effects of various parameters on the momentum and heat transfer characteristics have been studied, and the numerical results are presented graphically for the various values of the parameters entering the problem into consideration.

\section{Model Description}

The unsteady two-dimensional BFD flow of a viscous incompressible fluid past a stretching sheet with an acute angle $\alpha$ to the vertical is considered.

Where $u$ and $v$ are the velocity components along $X$-direction and $Y$-direction, respectively. The $X$-axis is considered along the plate and $Y$-axis is taken normal to it (see Figure 1). Initially $(t=0)$, the sheet is stretched with velocity $U_{w}(x, t)=\frac{a x}{(1-c t)}$ along the $X$-axis, whereas the origin is kept fixed in the fluid medium of ambient temperature 
$T_{\infty}$, and $T_{w}$ is the stretching surface temperature. A magnetic field of uniform strength $B(t)$ is acting normal to the direction of the flow, with an acute angle $\xi$. The magnetic Reynold's number is assumed as much less than unity, and the flow is considered twodimensional, therefore the induced magnetic field can be neglected in comparison to the applied magnetic field. Moreover, the fluids exhibit polarization due to the incorporated principles of FHD, and the applied magnetic field is assumed to be strong enough to attain equilibrium magnetization. The velocity slip, thermal slip, viscous dissipation parameter, and ferromagnetic interaction parameter have been taken into account. The boundary layer equations of the fluid and energy equation for the problem can be written as $[1,26,27]$.

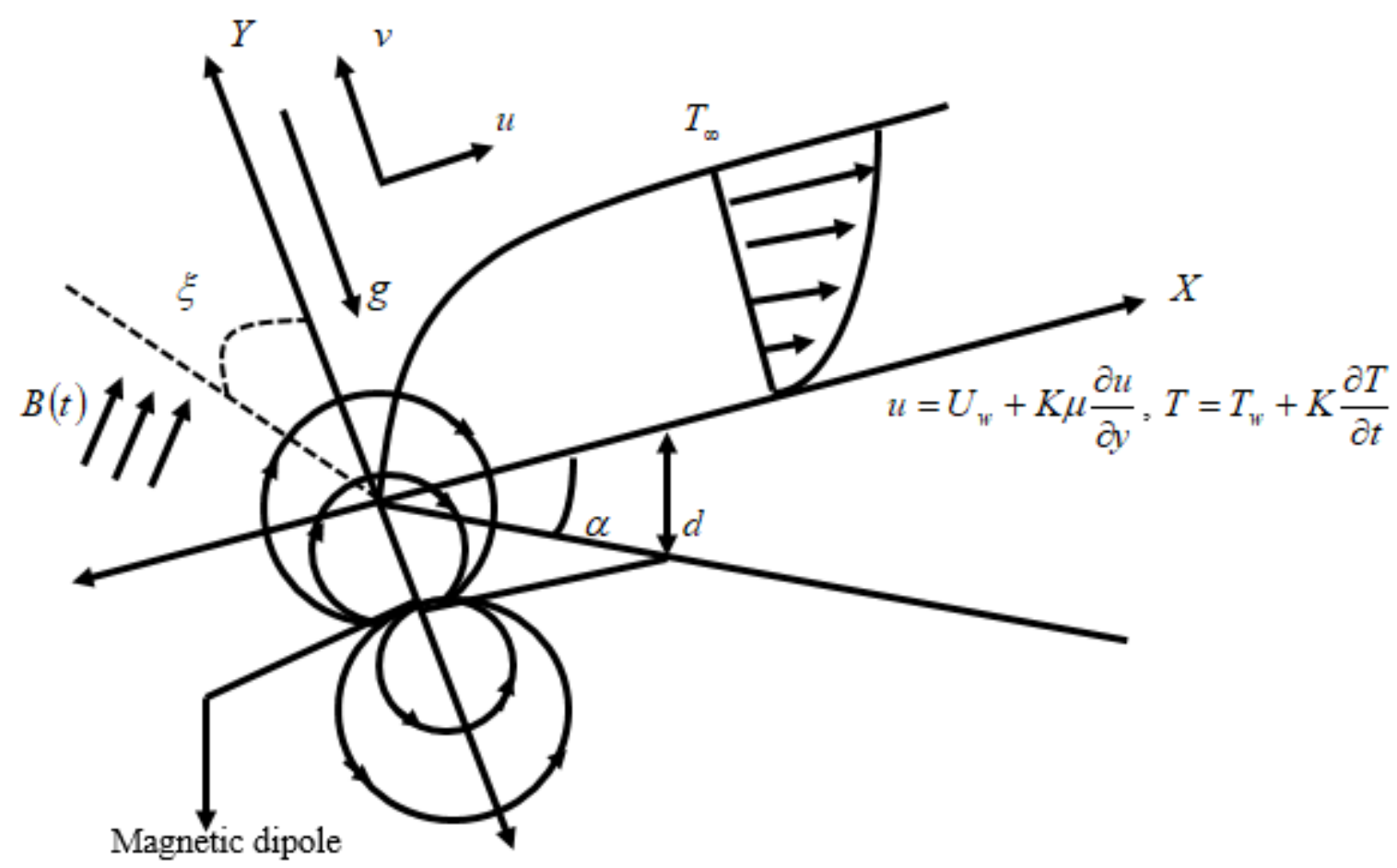

Figure 1. Physical sketch of the problem.

Conservation of mass:

$$
\frac{\partial u}{\partial x}+\frac{\partial v}{\partial y}=0
$$

Momentum conservation:

$$
\frac{\partial u}{\partial t}+u \frac{\partial u}{\partial x}+v \frac{\partial u}{\partial y}=\vartheta \frac{\partial^{2} u}{\partial y^{2}}-\frac{\sigma B^{2}(t)}{\rho} \sin ^{2} \xi u-\frac{\vartheta}{k_{1}(t)} u+\frac{\mu_{0}}{\rho} M_{1} \frac{\partial H}{\partial x}+g \beta^{*}\left(T-T_{\infty}\right) \cos \alpha
$$

Energy (Heat) conservation:

$$
\rho C_{p}\left(\frac{\partial T}{\partial t}+u \frac{\partial T}{\partial x}+v \frac{\partial T}{\partial y}\right)+\mu_{0} T \frac{\partial M_{1}}{\partial T}\left(u \frac{\partial H}{\partial x}+v \frac{\partial H}{\partial y}\right)=K \frac{\partial^{2} T}{\partial y^{2}}-\frac{\partial q_{r}}{\partial y}+q^{m}+\rho \vartheta\left(\frac{\partial u}{\partial y}\right)^{2}
$$

Here, $\rho$ is the biomagnetic fluid density, $B(t)=B_{0}(1-c t)^{\frac{-1}{2}}$, where $B_{0}$ is a constant representing the magnetic field strength at $t=0, k_{1}(t)=k_{2}(1-c t)$ is the time dependent permeability parameter, $k_{2}$ is the constant permeability of the medium, $g$ is the acceleration due to gravity, $\beta^{*}$ is the coefficient of thermal expansion, $K$ is the thermal conductivity, $C_{p}$ is the specific heat at constant pressure, $\vartheta$ is the kinematic coefficient of viscosity, $\sigma$ is the electrical conductivity, $q_{r}$ is the radiative heat flux, $M_{1}$ is the magnetization, $H$ is the magnetic field of the fluid, and $T$ is the temperature of the field. 
The boundary conditions for the problem can be written as: $[27,28]$

$$
\left.\begin{array}{c}
y=0: u=U_{w}+N \mu \frac{\partial u}{\partial y}, v=V_{w}, T=T_{w}+K \frac{\partial T}{\partial y} \\
y \rightarrow \infty: u \rightarrow 0, T \rightarrow T_{\infty}
\end{array}\right\}
$$

Here, $U_{w}(x, t)=\frac{a x}{(1-c t)}$ is the stretching velocity, $T_{w}(x, t)=T_{\infty}+\frac{b x}{(1-c t)}$ is the surface temperature. Where $a, b, c$ are the constants such that $a>0, b>0, c \geq 0$ and $c t<1$.

In Equation (4), $V_{w}$ represents the blood velocity at the wall and is equal to injection/suction velocity given by

$$
V_{w}=-\sqrt{\frac{\vartheta U_{w}}{x}} f(0)
$$

As it is implied by Equation (5), the mass transfer at the sheet of the wall takes place with a velocity $V_{w}$. For the case of injection, it is considered that $V_{w}>0$, whereas $V_{w}<0$ is considered for the case of suction. $N=N_{0}(1-c t)^{\frac{1}{2}}$ is the velocity slip factor, $\mu$ is the coefficient of viscosity, $K=K_{0}(1-c t)^{\frac{1}{2}}$ is the thermal slip factor. The no-slip conditions hold when $N=K=0$.

Using the Rosseland approximation [27], the radiation heat flux $q_{r}$ is simplified as

$$
q_{r}=\frac{4 \sigma^{*}}{3 k^{*}} \frac{\partial T^{4}}{\partial y}
$$

where $\sigma^{*}$ and $k^{*}$ are the Stefan-Boltzman constant and the mean absorption co-efficient, respectively.

Considering that the temperature differences within the flow are such that the term $T^{4}$ may be expressed as a linear function of the temperature, $T^{4}$ is expanded in a Taylor series about $T_{\infty}$. By neglecting the higher order terms beyond the first degree in $\left(T-T_{\infty}\right)$, it is obtained that

$$
T^{4} \cong 4 T_{\infty}^{3} T-3 T_{\infty}^{4}
$$

The non-uniform heat source $/ \operatorname{sink} q^{m}$ is defined as

$$
q^{m}=\frac{K U_{w}}{x \vartheta}\left[A^{*}\left(T_{w}-T_{\infty}\right) f^{\prime}+B^{*}\left(T-T_{\infty}\right)\right]
$$

where $A^{*}$ and $B^{*}$ are the coefficient of a space- and temperature-dependent heat source/sink, respectively. The case of $A^{*}>0, B^{*}>0$ corresponds to internal heat generation, and that of $A^{*}<0, B^{*}<0$ corresponds to internal heat absorption. Physically, the role of a heat source in a fluid transport is to enhance its thermal conductivity, which consequently results in increased fluid temperature. On the other hand, heat sink decreases the thermal conductivity, which results in a decrease in the temperature of the fluid.

By substituting (5) and (6) into (3), the energy equation is reduced to

$$
\rho C_{p}\left(\frac{\partial T}{\partial t}+u \frac{\partial T}{\partial x}+v \frac{\partial T}{\partial y}\right)+\mu_{0} T \frac{\partial M_{1}}{\partial T}\left(u \frac{\partial H}{\partial x}+v \frac{\partial H}{\partial y}\right)=K \frac{\partial^{2} T}{\partial y^{2}}-\frac{16 \sigma^{*} T_{\infty}^{3}}{3 k^{*}} \frac{\partial^{2} T}{\partial y^{2}}+q^{m}+\rho \vartheta\left(\frac{\partial u}{\partial y}\right)^{2}
$$

The term $\mu_{0} M_{1} \frac{\partial H}{\partial x}$ in Equation (2) denotes the component of magnetic force per unit volume. This term is heavily dependent on the presence of a magnetic gradient, and, when the magnetic gradient is absent, this force vanishes. The heating due to adiabatic magnetization is represented by the second term, on the left hand side of the thermal energy Equation (8). The components $H_{x}$ and $H_{y}$ of the magnetic field $\bar{H}=\left(H_{x}, H_{y}\right)$, which are due to a magnetic dipole, are given by $[29,30]$

$$
H_{x}(x, y)=-\frac{\partial V}{\partial x}=\frac{\gamma}{2 \pi} \frac{x^{2}-(y+d)^{2}}{\left[x^{2}+(y+d)^{2}\right]^{2}}
$$




$$
H_{y}(x, y)=-\frac{\partial V}{\partial y}=\frac{\gamma}{2 \pi} \frac{2 x(y+d)}{\left[x^{2}+(y+d)^{2}\right]^{2}}
$$

where $V=\frac{\alpha_{1}}{2 \pi} \frac{x}{x^{2}+(y+d)^{2}}$ is a scalar potential of the magnetic dipole, $\gamma=\alpha_{1}$ and $\alpha_{1}$ is a dimensionless distance defined as $\alpha_{1}=\left(\frac{U_{w v}}{x \vartheta}\right)^{\frac{1}{2}} d$.

Thus, the magnetic field strength intensity $\|\bar{H}\|=H$ is given by

$$
H(x, y)=\left[H_{x}^{2}+H_{y}^{2}\right]^{\frac{1}{2}}=\frac{\gamma}{2 \pi}\left[\frac{1}{(y+d)^{2}}-\frac{x^{2}}{(y+d)^{4}}\right]
$$

The corresponding gradients are given by

$$
\begin{gathered}
\frac{\partial H}{\partial x}=-\frac{\gamma}{2 \pi} \frac{2 x}{(y+d)^{2}} \\
\frac{\partial H}{\partial y}=\frac{\gamma}{2 \pi}\left[\frac{-2}{(y+d)^{3}}+\frac{4 x^{2}}{(y+d)^{5}}\right]
\end{gathered}
$$

The magnetization $M_{1}$ is generally determined by the fluid temperature provided that the applied magnetic field $\bar{H}$ is sufficiently strong enough to saturate the biomagnetic fluid. Anderson and Valnes [29] considered that the variation of magnetization $M_{1}$ with temperature $T$ can be approximated by the linear equation

$$
M_{1}=k\left(T-T_{\infty}\right),
$$

where $k$ is a constant.

To transform the momentum and energy equations, the following transformations are defined:

$$
\eta=\sqrt{\frac{U_{w}}{x \vartheta}} y ; \psi=\sqrt{x \vartheta U_{w}} f(\eta) ; \theta(\eta)=\frac{T-T_{\infty}}{T_{w}-T_{\infty}}
$$

Here, $\eta$ is the similarity variable, $\psi$ is the stream function, $f$ and $\theta$ are dimensionless quantities.

The continuity Equation (1) is satisfied by the stream function $\psi$ as

$$
u=\frac{\partial \psi}{\partial y}
$$

and

$$
v=-\frac{\partial \psi}{\partial x}
$$

Making use of Equation (9), Equations (2) and (8) can be written as

$$
\begin{aligned}
& f^{\prime \prime \prime}-f^{\prime 2}+f f^{\prime \prime}-A\left[f^{\prime}+\frac{1}{2} \eta f^{\prime \prime}\right]-M f^{\prime} \sin ^{2} \xi-\frac{1}{k_{3}} f^{\prime}-\frac{2 \beta \theta}{\left(\eta+\alpha_{1}\right)^{4}}+G r \theta \cos \alpha=0 \\
& \frac{(1+R)}{\operatorname{Pr}} \theta^{\prime \prime}-A\left(\theta+\frac{1}{2} \eta \theta^{\prime}\right)-f^{\prime} \theta+f \theta^{\prime}-\frac{2 \beta \lambda(\varepsilon+\theta)}{\operatorname{Pr}\left(\eta+\alpha_{1}\right)^{3}} f+\frac{\left(A^{*} f^{\prime}+B^{*} \theta\right)}{\operatorname{Pr}}+E c f^{\prime \prime 2}=0
\end{aligned}
$$

The boundary conditions are transformed to:

$$
\left.\begin{array}{c}
\eta=0: f=S, f^{\prime}=1+S_{f} f^{\prime \prime}, \theta=1+S_{t} \theta^{\prime} \\
\eta \rightarrow \infty: f^{\prime} \rightarrow 0, \theta \rightarrow 0
\end{array}\right\}
$$


In Equation (12), $S<0$ and $S>0$ correspond to injection and suction, respectively. In the equation written above, primes denote derivatives with respect to $\eta \cdot S_{f}=N \rho \sqrt{a \vartheta}$ and $S_{t}=K \sqrt{\frac{a}{\vartheta}}$ are the non-dimensional velocity slip factor and thermal slip factor, respectively.

Furthermore, $A=\frac{c}{a}$ is the unsteadiness parameter, $\operatorname{Pr}=\frac{\mu C_{p}}{K}$ is the Prandtl number, $\lambda=\frac{a \mu^{2}}{\rho K(1-c t)\left(T_{w}-T_{\infty}\right)}$ is the viscous dissipation parameter, $\varepsilon=\frac{T_{\infty}}{T_{w}-T_{\infty}}$ is the dimensionless curie temperature, $\beta=\frac{\gamma}{2 \pi} \frac{\mu_{0} \rho k\left(T_{w}-T_{\infty}\right)}{\mu^{2}}$ is the ferromagnetic interaction parameter, $k_{3}=\frac{a k_{2}}{\vartheta}$ is the permeability parameter, $M=\frac{\sigma B_{0}^{2}}{a \rho}$ is the magnetic field parameter, $R=\frac{16 \sigma^{*} T_{\infty}^{3}}{3 K k^{*}}$ is the radiation parameter, $G r=\frac{x g \beta^{*}\left(T_{w}-T_{\infty}\right)}{U_{\infty}^{2}}$ is the Grashof number, $E c=\frac{U_{w}^{2}}{C_{p}\left(T_{w}-T_{\infty}\right)}$ is the Eckert number, $\alpha_{1}=\sqrt{\frac{U_{w}}{x \vartheta}} d$ is the dimensionless distance, and $\operatorname{Re}=\frac{x U_{w}}{v}$ is the local Reynolds number.

The skin friction coefficient and the Nusselt number constitute important characteristics of the flow, defined as:

$$
C_{f}=\frac{\tau_{w}}{\frac{u_{\infty}^{2}}{2} \rho} ; N u=\frac{x q_{w}}{K\left(T_{w}-T_{\infty}\right)}
$$

where, the wall stress $\tau_{w}$ and the heat transfer $q_{w}$ from the sheet are given by

$$
\tau_{w}=\mu\left(\frac{\partial u}{\partial y}\right)_{y=0} ; q_{w}=-K\left(\frac{\partial T}{\partial y}\right)_{y=0}
$$

Using the similarity variables (9), it is obtained that:

$$
C_{f}=2 \operatorname{Re}^{-\frac{1}{2}} f^{\prime \prime}(0) ; N u=-\operatorname{Re}^{\frac{1}{2}} \theta^{\prime}(0)
$$

\section{Numerical Method}

The numerical solution of the set of nonlinear ordinary differential Equations (10) and (11) subject to boundary conditions (12) is utilized by using bvp4c function technique MATLAB package. We consider $f=y_{1}, f^{\prime}=y_{2}, f^{\prime \prime}=y_{3}, \theta=y_{4}, \theta^{\prime}=y_{5}$. Then, the governing equations are transformed into the following system of first order ordinary differential equations:

$$
\left.\begin{array}{c}
f^{\prime}=y_{2} \\
f^{\prime \prime}=y_{2}^{\prime}=y_{3} \\
f^{\prime \prime \prime}=y_{3}^{\prime}=A\left(y_{2}+\frac{\eta}{2} y_{3}\right)+y_{2}^{2}-y_{1} y_{3}+M y_{2} \sin ^{2} \xi+\frac{y_{2}}{k_{3}}+\frac{2 \beta y_{4}}{\left(\eta+\alpha_{1}\right)^{4}}-G r y_{4} \cos \alpha \\
\theta^{\prime}=y_{5} \\
\theta^{\prime \prime}=y_{5}^{\prime}=\frac{\operatorname{Pr}}{(1+R)}\left\{A\left(y_{4}+\frac{\eta}{2} y_{5}\right)+y_{2} y_{4}-y_{1} y_{5}\right\}+\frac{2 \beta \lambda y_{1}}{(1+R)} \frac{\left(\varepsilon+y_{4}\right)}{(\eta+\alpha)^{3}}-\frac{1}{(1+R)}\left[A^{*} y_{2}+B^{*} y_{4}\right]-\frac{\operatorname{Pr} E c}{(1+R)} y_{3}^{2}
\end{array}\right\}
$$

Along with the initial boundary conditions:

$$
y_{1}(0)=S, y_{2}(0)=1+S_{f} y_{3}(0), y_{4}(0)=1+S_{t} y_{1}(0), y_{2}(\infty)=0, y_{4}(\infty)=0
$$

Equations (13) and (14) are integrated numerically as an initial value problem to a given terminal point. All the calculations are made by using bvp4c function available in MATLAB software.

\section{Parameter Estimation}

In this study, the unsteady biomagnetic fluid flow along a two-dimensional stretching/shrinking sheet under the action of a magnetic field is investigated numerically. In order to achieve the numerical solution, it is necessary to determine some specific values for the dimensionless parameters, such as the Prandtl number, the unsteadiness parameter, the magnetic field parameter, the permeability parameter, the radiation parameter, the ferromagnetic interaction parameter, the Grashof number, the Eckert number, the suc- 
tion/injection parameter, the non-dimensional velocity-slip factor, the non-dimensional thermal slip factor, the acute angle of magnetic field, the inclination angle, the co-efficient of space and temperature.

Many researchers have, in scientific literatures, reported various values of the abovementioned dimensionless parameters. It is understood that, for human blood, the following data are considered:

$$
\mu=3.2 \times 10^{-3} \mathrm{kgm}^{-1} \mathrm{~s}^{-1}, C_{p}=14.65 \mathrm{jkg}^{-1} \mathrm{~K}^{-1}, k=2.2 \times 10^{-3} \mathrm{j}(\mathrm{msK})^{-1}
$$

in [31-33], where, human body temperature is considered to be $T_{w}=37^{\circ} \mathrm{C}$ and the body Curie temperature is considered to be $T_{\infty}=41^{\circ} \mathrm{C}$. For this value of temperature, the dimensionless temperature is $\varepsilon=78.5$.

Using these values, we have $\operatorname{Pr}=\frac{\mu C_{p}}{k}=21$.

That is, for human blood flow, the Prandtl number is 21.

For the results presented in the following Figures $2-39$, we consider the values of the dimensionless parameters entering into the problem under consideration as follows:

(1) Unsteadiness parameter $A=0.0,0.5,0.9$ as in [34]

(2) Radiation parameter $R=1,2,3$ as in $[24,28,35,36]$

(3) Prandtl number $\operatorname{Pr}=17,21,25$ as in $[29,37,38]$

(4) Ferromagnetic interaction parameter $\beta=1,4,7$ as in $[30,37,38]$

(5) Dimensionless distance $\alpha_{1}=1$ as in $[34,36,38]$

(6) Viscous dissipation parameter $\lambda=1.6 \times 10^{-14}$ as in $[24,37,38]$

(7) Dimensionless curie temperature $\varepsilon=78.5$ as in $[29,37,38]$

(8) Suction/injection parameter $S=-0.1,0.5,1.0,1.5$ as in $[20,27]$

(9) Magnetic field parameter $M=1,2,3$ as in [24,31,38]

(10) Permeability parameter $k_{3}=0.1,0.3,0.5$ as in $[27,31]$

(11) Eckert number $E c=1,2,3$ as in $[27,31,37,38]$

(12) Grashof number $G r=1,3,5$ as in [27,31]

(13) Non-dimensional velocity-slip factor $S_{f}=0.5,1.0,1.5$ as in $[27,31]$

(14) Non-dimensional thermal slip factor $S_{t}=0.5,1.0,1.5$ as in $[27,31]$

(15) Acute angle of magnetic field $\xi=0, \pi / 4, \pi / 2$ as in $[27,31,34]$

(16) Inclination angle $\alpha=0, \pi / 4, \pi / 2$ as in $[27,31]$

(17) Co-efficient of space $A^{*}=0,2,4$ as in $[27,31]$

(18) Co-efficient of temperature $B^{*}=0,2,4$ as in $[27,31]$

\section{Results and Discussion}

In order to assess the validity of the numerical results, the values of local Nusselt number $-\theta^{\prime}(0)$ have been compared with the existing works of Magyari and Keller [35], El-Aziz [36], Bidin and Nazar [8], and Anwar Ishak [10] by setting $S=0, S_{f}=0, S_{t}=0$, $\beta=0, \lambda=0, A=0, k_{3} \rightarrow \infty, G r=0, E c=0, A^{*}=0, B^{*}=0, \xi=\pi / 2$. It is apparent from the Table 1 that the numerical scheme and the coding used give results in good agreement with the abovementioned, previously published studies.

A comparison of the local Nusselt number $-\theta^{\prime}(0)$ for various values $R, M$, Pr.

Figures 2 and 3 show the velocity and temperature distributions with various values of the unsteadiness parameter $A$. From Figure 2, it is observed that the velocity profiles are decreased as the unsteadiness parameter is increasing. This is justified because the accompanying reduction in the thickness of the momentum in the boundary layer. Moreover, from Figure 3, it is obtained that the temperature profiles are decreased significantly as the unsteadiness parameter is increased. The fact is that, when the unsteadiness parameter is increased, less heat is transferred from the sheet to the fluid. 
Table 1. Comparisons with previous studies.

\begin{tabular}{cccccccc}
\hline$R$ & $\boldsymbol{M}$ & $\mathbf{P r}$ & Magyari and Keller [35] & El-Aziz [36] & Bidin and Nazar [8] & Anwar Ishak [10] & Present Results \\
\hline 0 & 1 & 1 & -0.954782 & -0.954785 & -0.9548 & -0.9548 & -0.954806 \\
\hline & & & & -1.4714 & -1.4715 & -1.471442 \\
\hline & & & -1.869075 & -1.869074 & -1.8691 & -1.8691 & -1.869057 \\
\hline & & 5 & -2.500135 & -2.500132 & & -2.5001 & -2.50018 \\
\hline & 10 & -3.660379 & -3.660372 & -0.6604 & -3.660369 \\
\hline 1 & 1 & 1 & & & -0.5315 & -0.5312 & -0.861094 \\
\hline & & & & & -0.4505 & -0.450620 \\
\hline
\end{tabular}

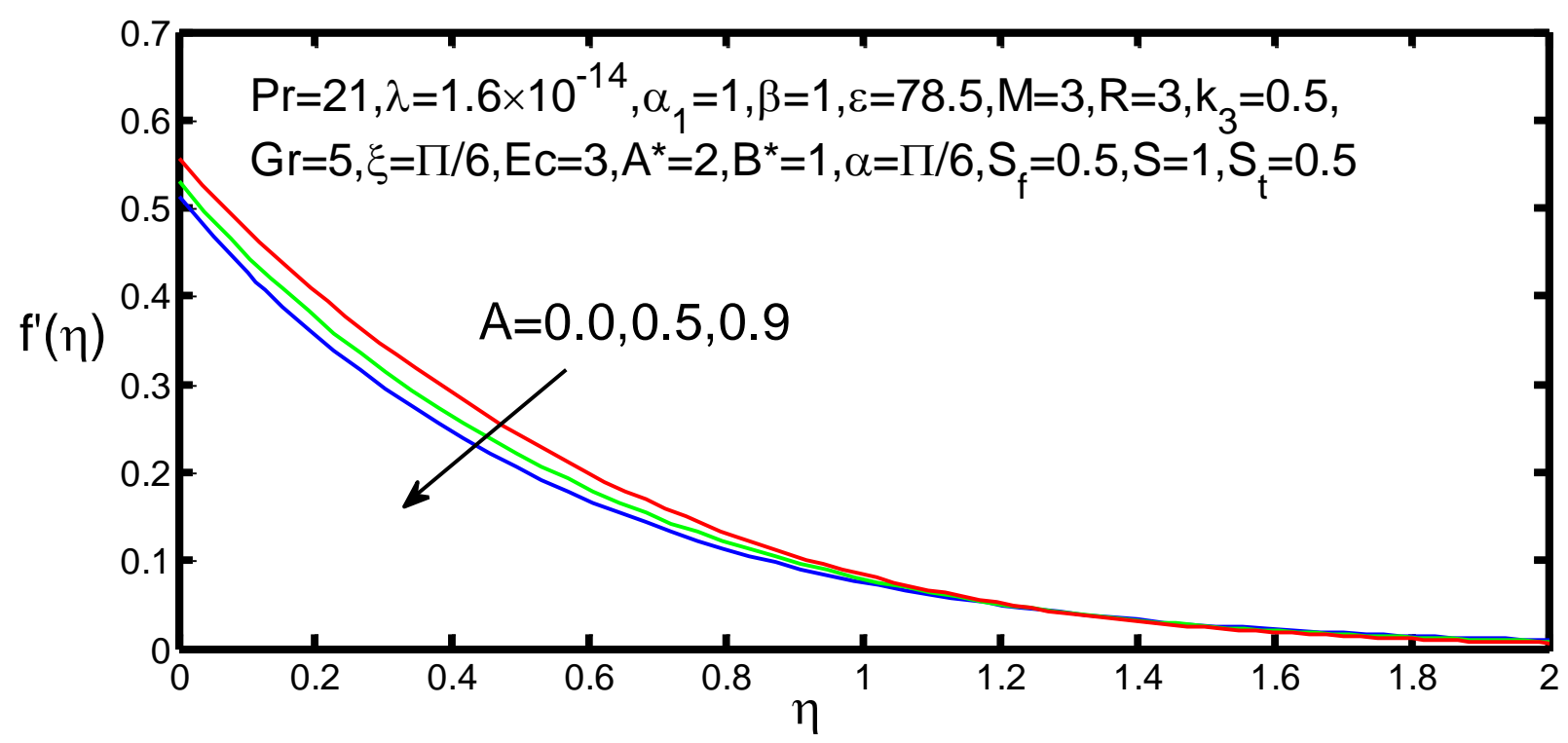

Figure 2. Velocity profile $f^{\prime}(\eta)$ for various values of $A$.

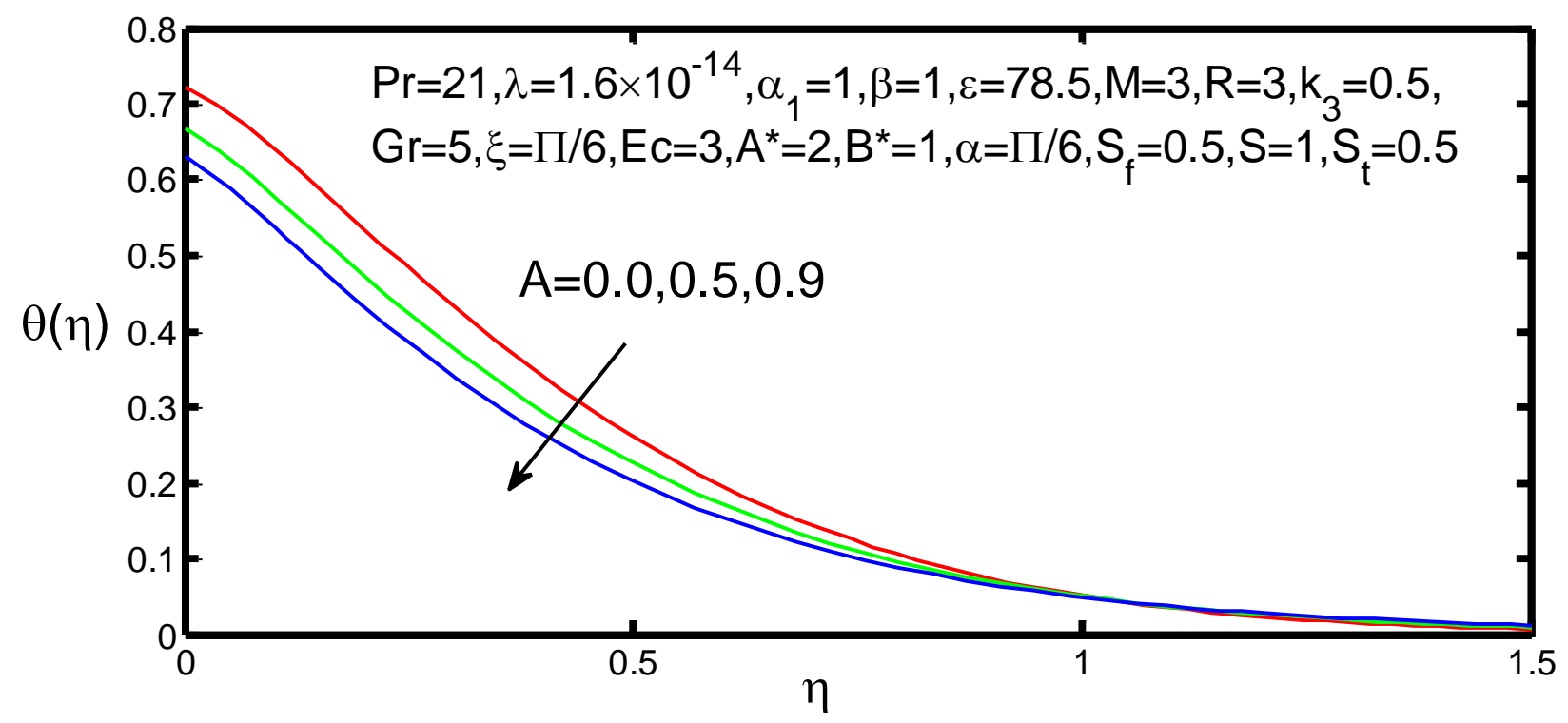

Figure 3. Temperature profile $\theta(\eta)$ for various values of $A$.

Figures 4 and 5 show the velocity and temperature profiles for various values of the radiation parameter $R$. From Figures 4 and 5 , it is observed that an increment in radiation 
parameter $R$ results in a decrement in the fluid velocity profile, whereas the temperature profile increases. The temperature profile is increased because the effect of the radiation parameter is to enhance heat transfer. The thermal boundary layer thickness is increased with the increment of the thermal radiation.

The velocity and temperature profiles with various values of Prandtl number Pr are shown in Figures 6 and 7. It is observed that an increment in Pr causes an increment in the velocity profile, whereas the temperature profile is decreased. This occurs because an increment in the Prandtl number means a decrement in the thermal diffusivity, and this phenomenon leads to the decreasing of energy ability that finally results in the reduction of the thermal boundary layer thickness.

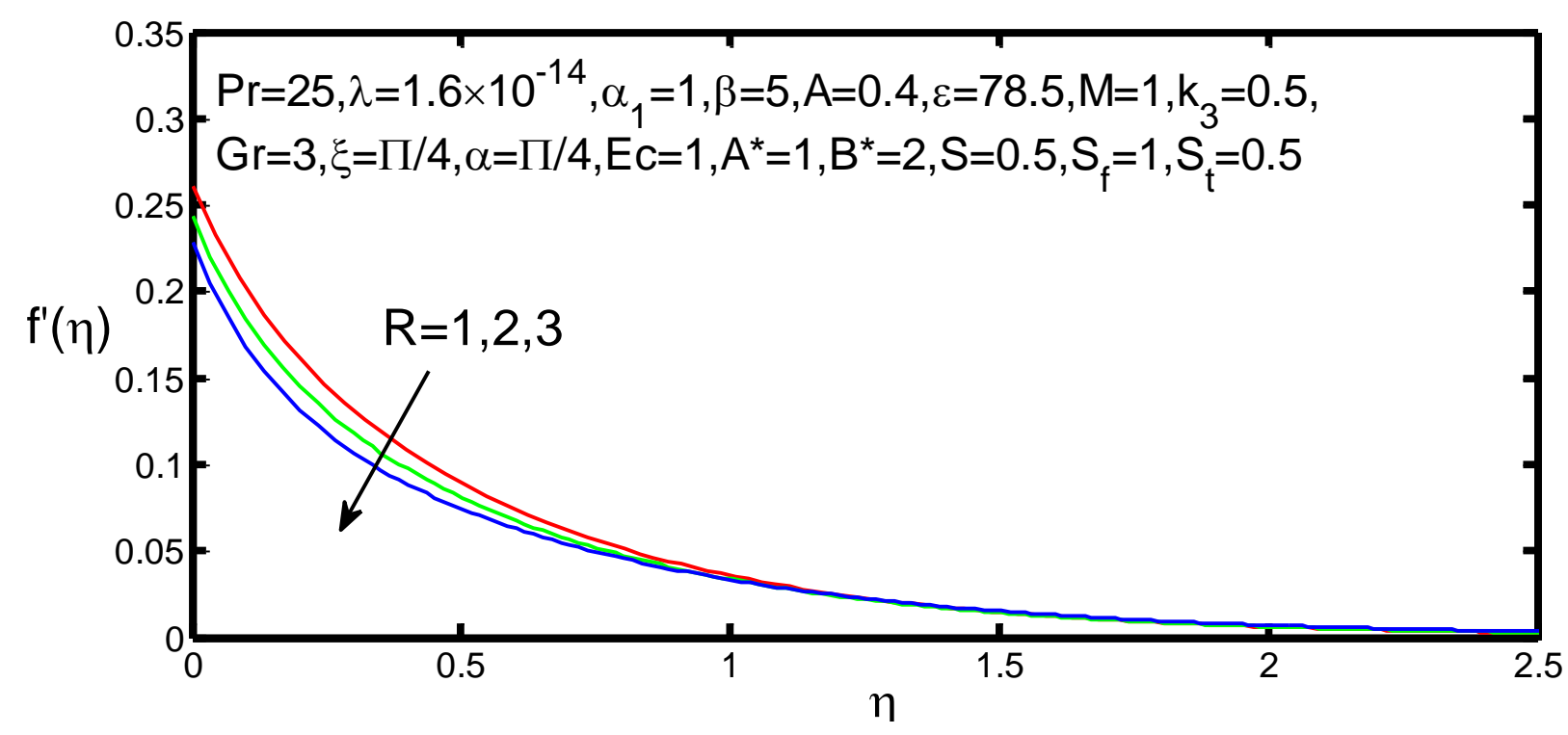

Figure 4. Velocity profile $f^{\prime}(\eta)$ for various values of $R$.

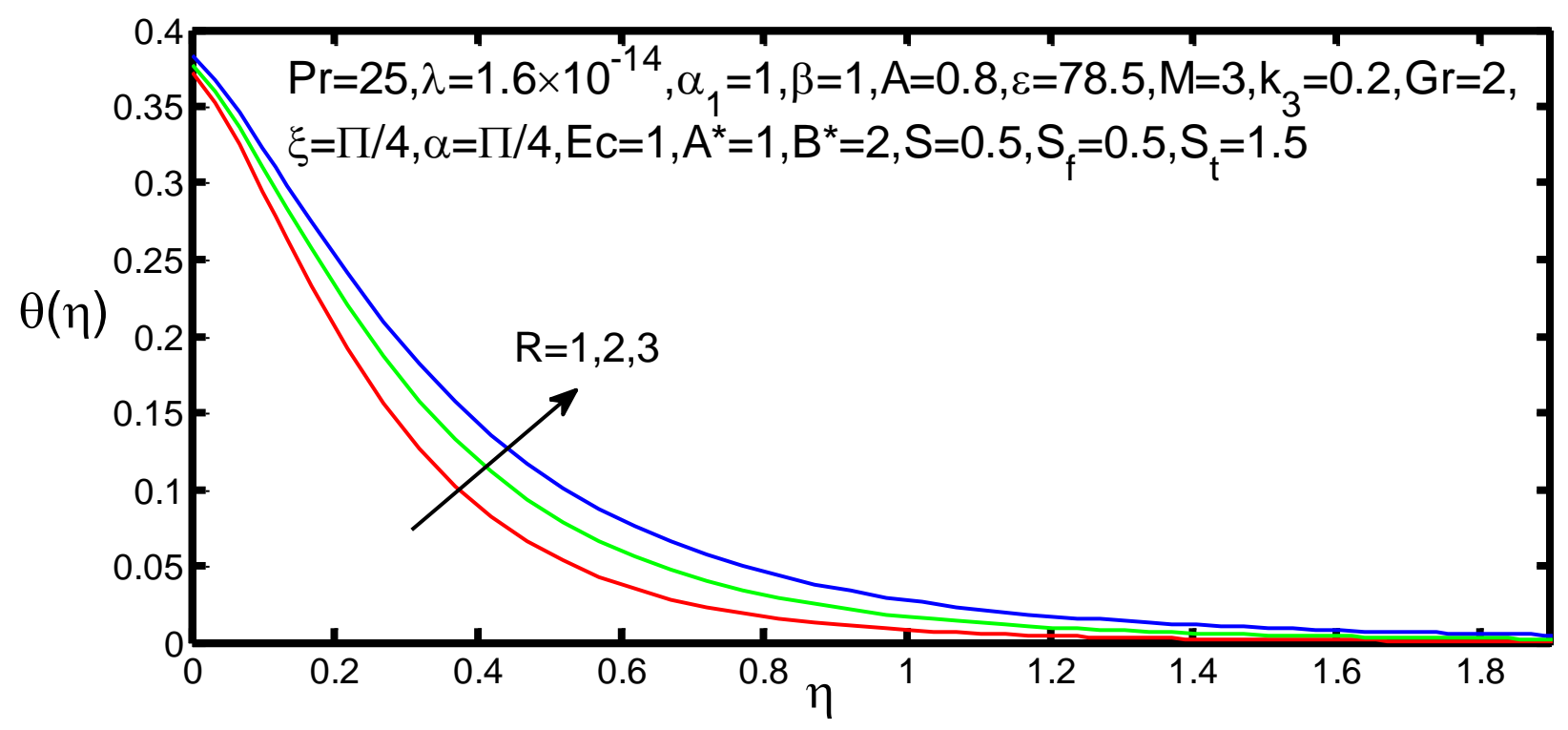

Figure 5. Temperature profile $\theta(\eta)$ for various values of $R$. 


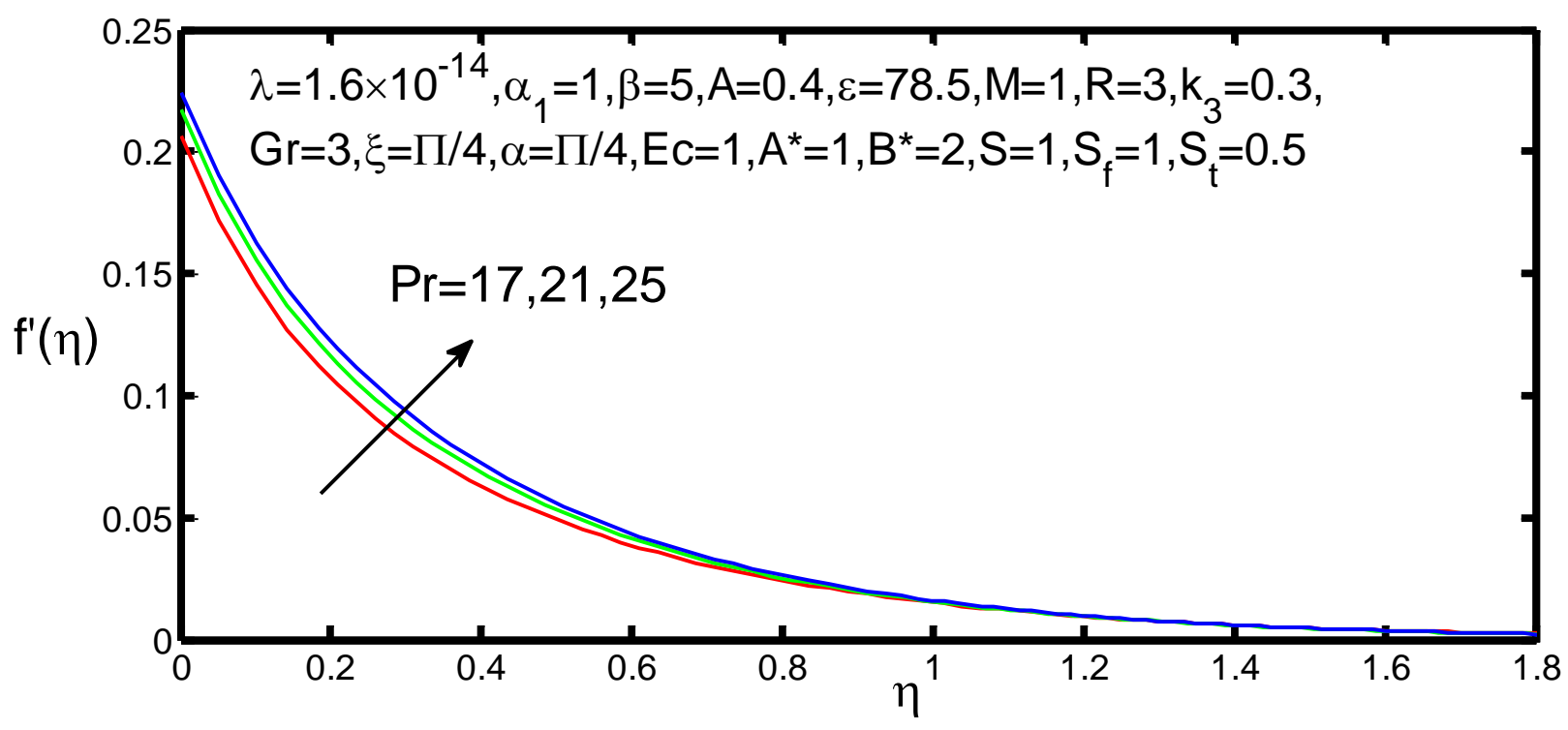

Figure 6. Velocity profile $f^{\prime}(\eta)$ for various values of Pr.

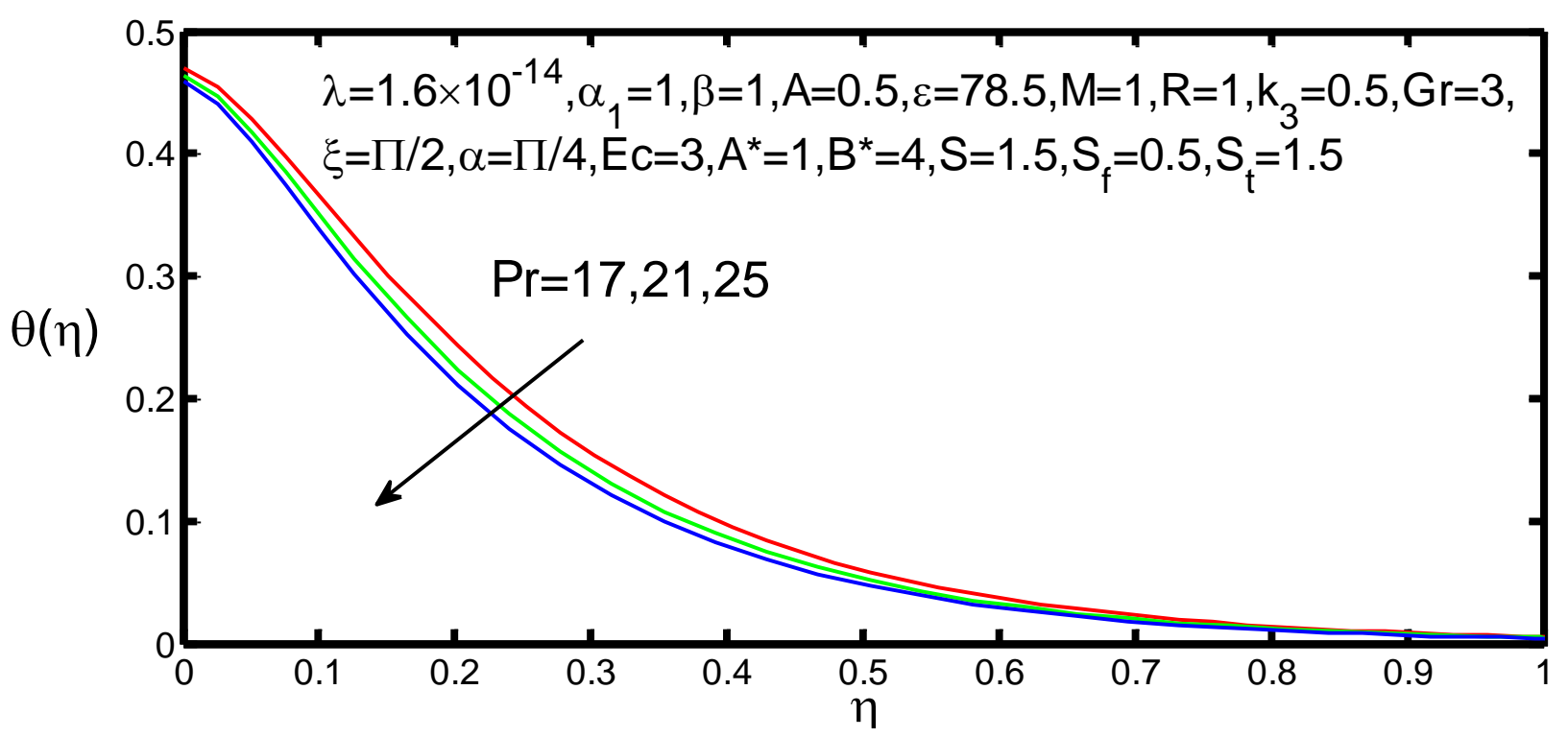

Figure 7. Temperature profile $\theta(\eta)$ for various values of Pr.

Figures 8 and 9 show the effect of the Grashof number Gr on the profiles of velocity and temperature. It was found that, with an increment in the Grashof number, which increases the velocity profile, the opposite is true for the temperature profile. This is due to the fact that an increase in the Grashof number means increment of the buoyancy forces which finally reduce the thermal boundary layer thickness.

The velocity and temperature profiles for various values of the Eckert number Ec are shown in Figures 10 and 11. The relationship between the kinetic energy in the flow and the enthalpy is expressed by the Eckert number. It assimilates the conversion of kinetic energy into internal energy by the work done against the viscous fluid stresses. The positive Eckert number implies cooling of the sheet. Hence, greater viscous dissipative heat causes a rise in temperature as well as the velocity, both of which are evident in Figures 10 and 11. 


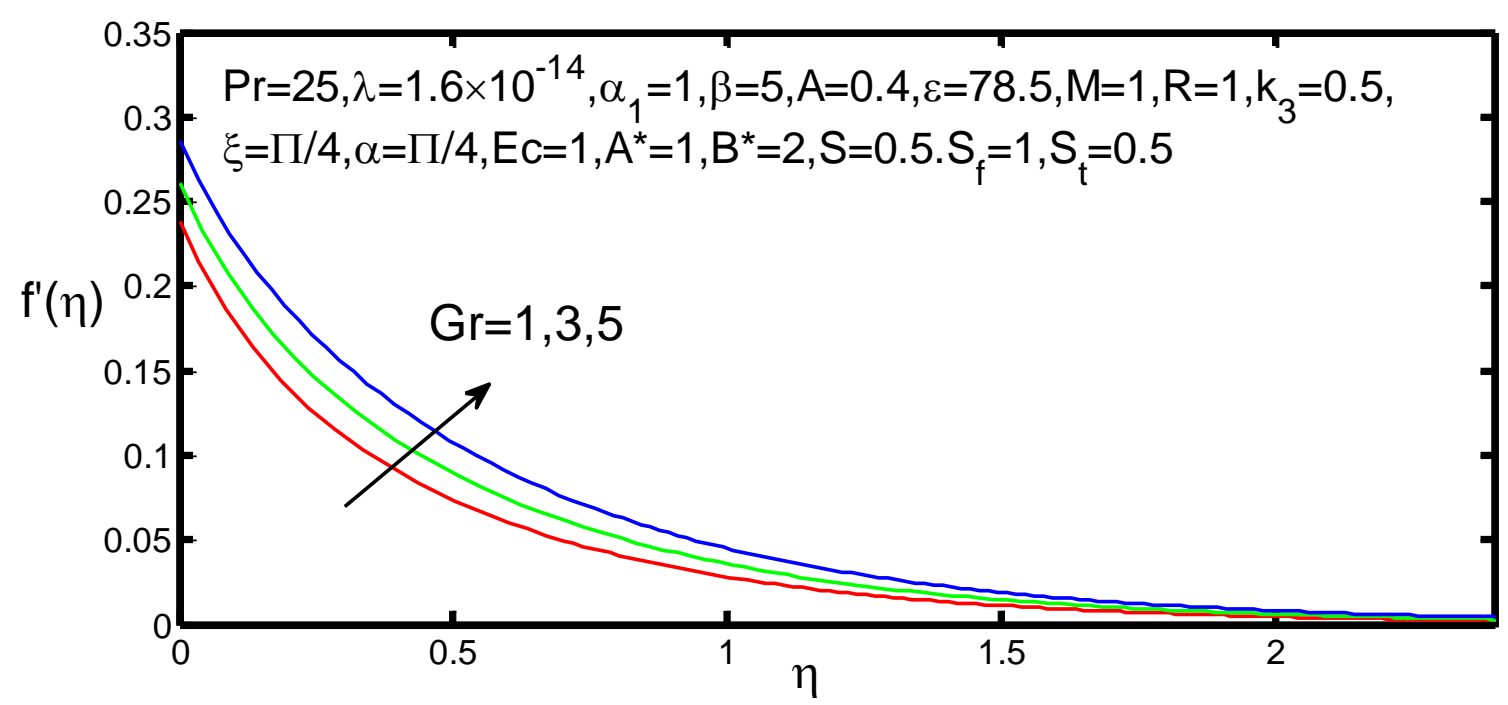

Figure 8. Velocity profile $f^{\prime}(\eta)$ for various values of $G r$.



Figure 9. Temperature profile $\theta(\eta)$ for various values of $G r$.

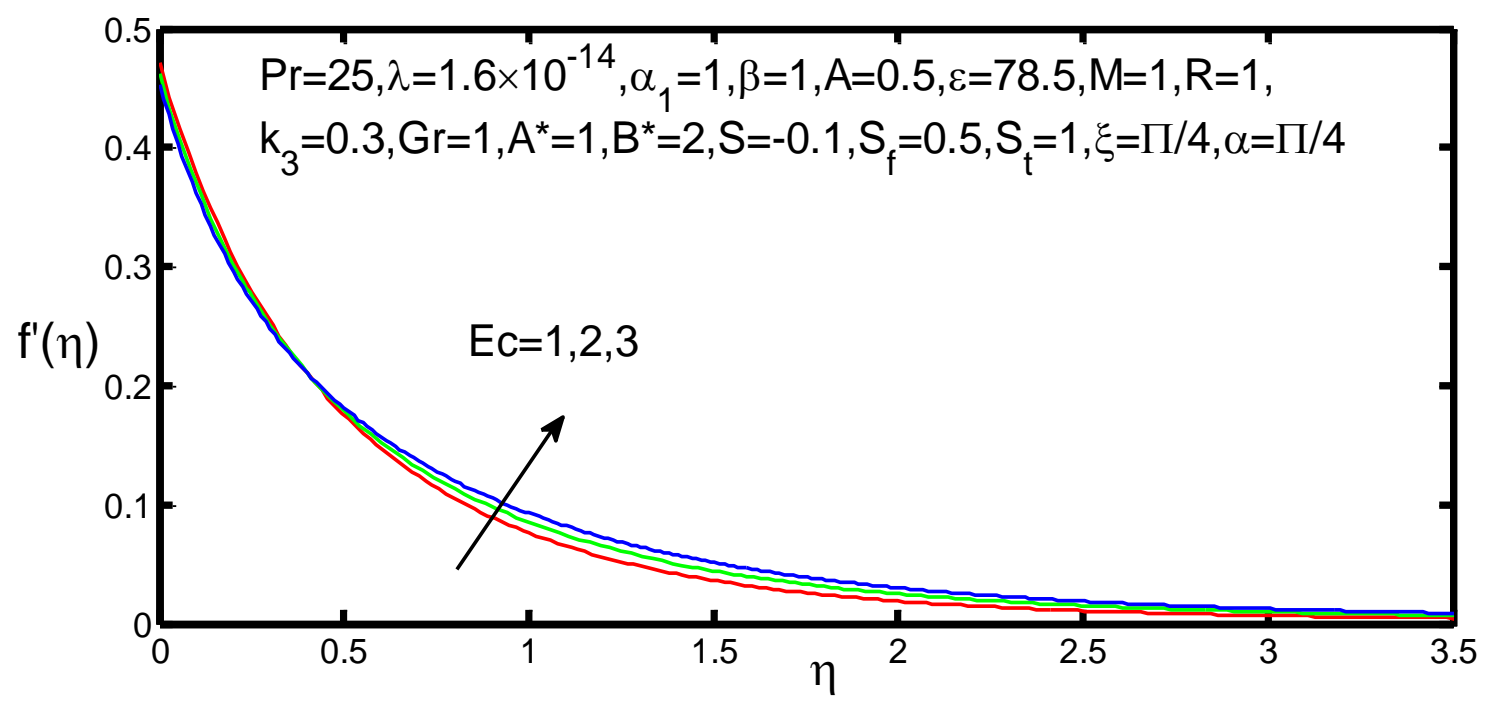

Figure 10. Velocity profile $f^{\prime}(\eta)$ for various values of $E c$. 


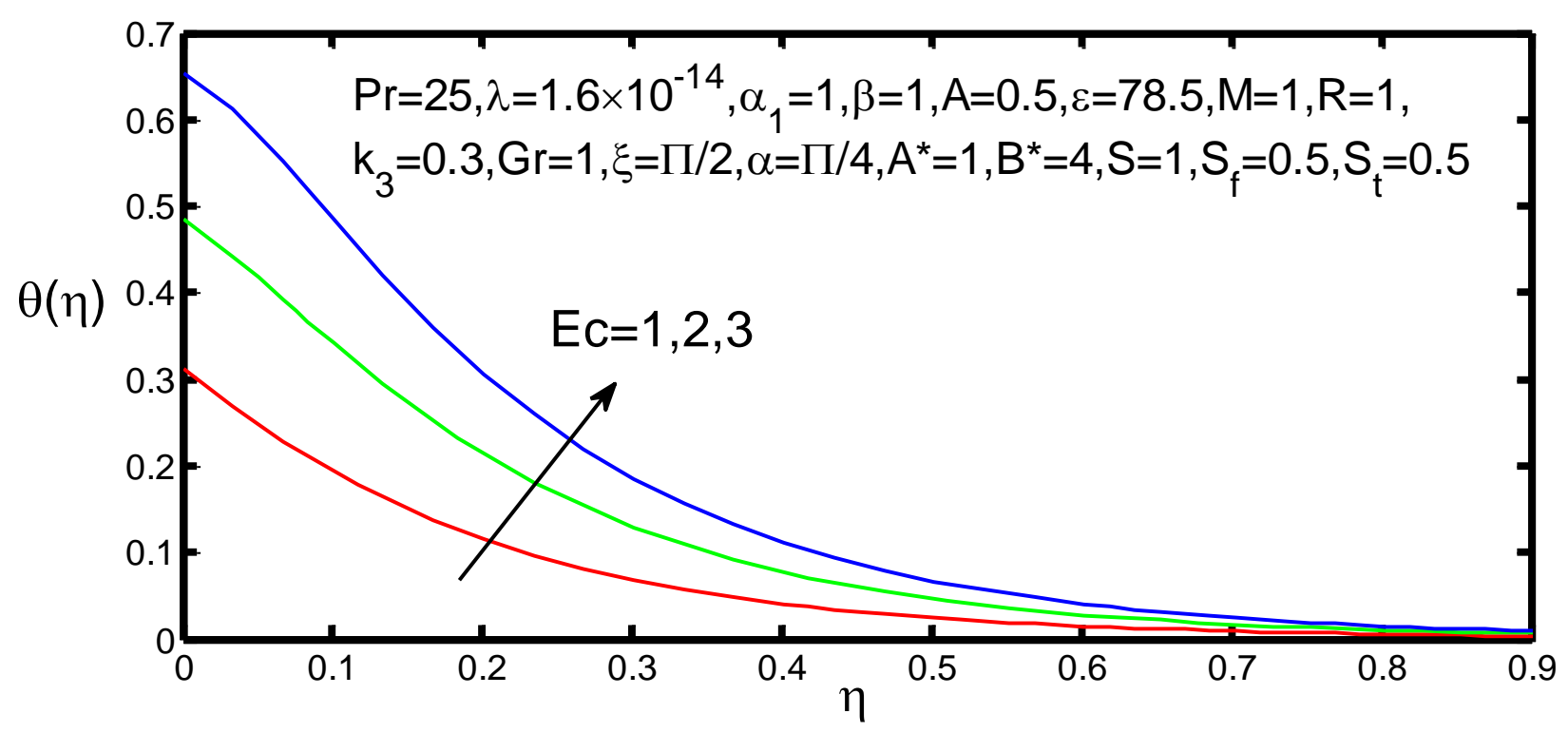

Figure 11. Temperature profile $\theta(\eta)$ for various values of $E c$.

Figures 12 and 13 show the effect of the suction/injection parameter $S$ on the velocity and temperature profiles. From the figures, it is observed that the momentum boundary layer thickness is decreased with increasing values of $S$. It is expected that the increment of the suction results in the decrement of the thickness of the hydrodynamic boundary layer. It also illustrates that an increment in $S$ decreases the temperature profiles in the flow region. This is due to the fact that, as the suction is increased, more warm fluid is taken away from the fluid region, causing a reduction in the thermal boundary layer thickness.

Figures 14 and 15 show the effect of velocity slip parameter $S_{f}$ on the velocity and temperature profiles. From the Figure 14, it is observed that the presence of velocity slip within the boundary layer causes the velocity level along the sheet to decrease. This is happening because the quantity $1-f^{\prime}(0)$ increases monotonically with $S_{f}$. We also observe that the temperature profile decreases, as shown in Figure 15.

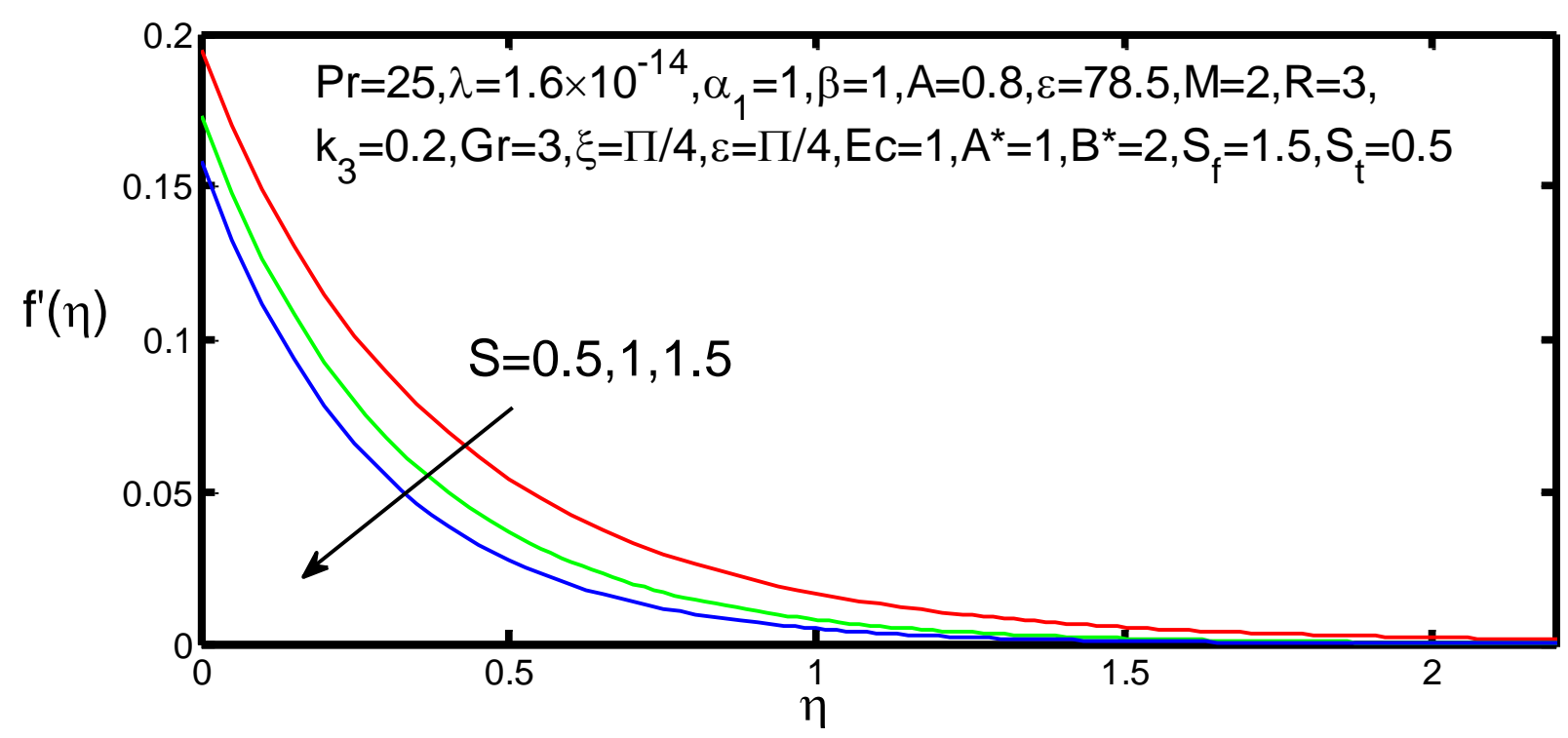

Figure 12. Velocity profile $f^{\prime}(\eta)$ for various values of $S$. 


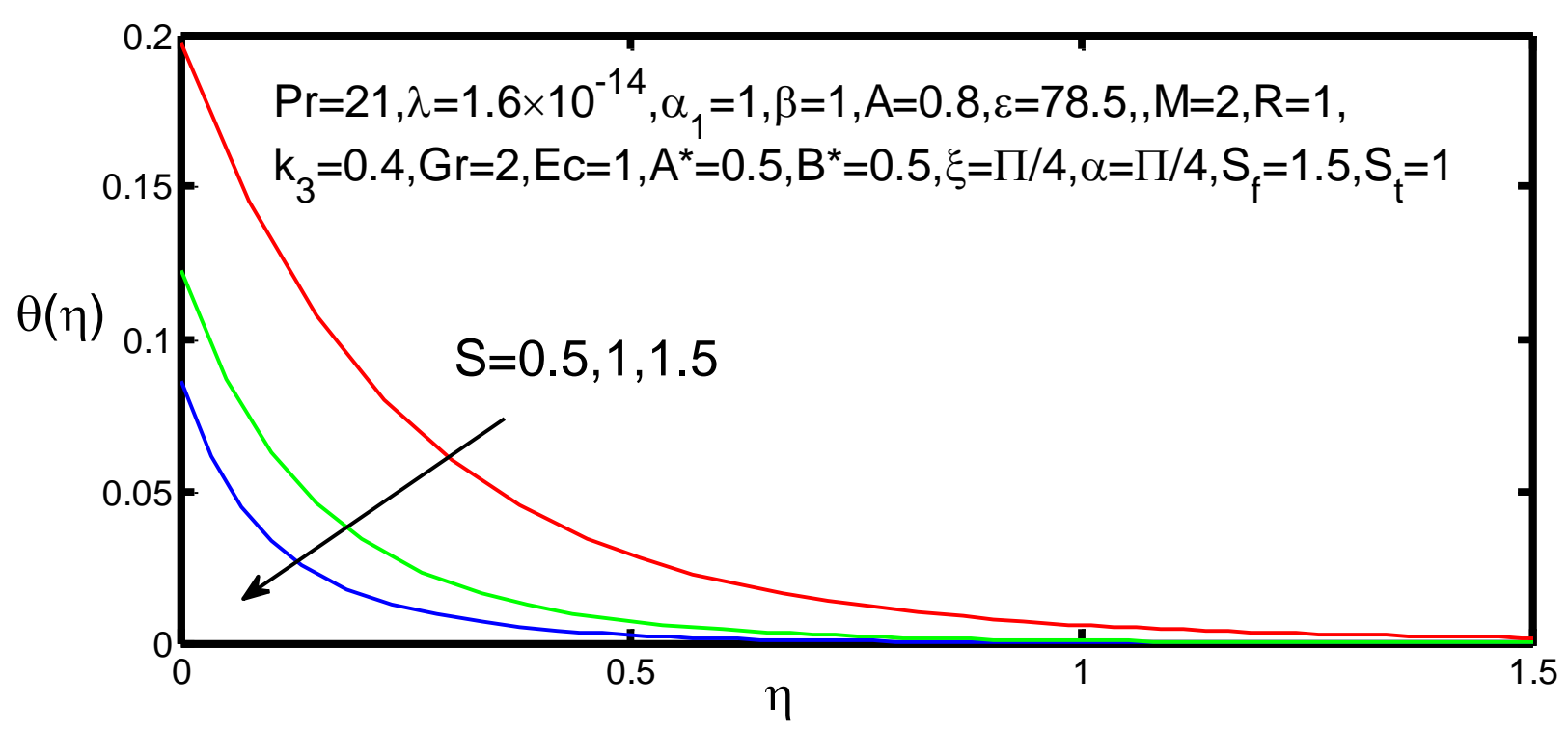

Figure 13. Temperature profile $\theta(\eta)$ for various values of $S$.

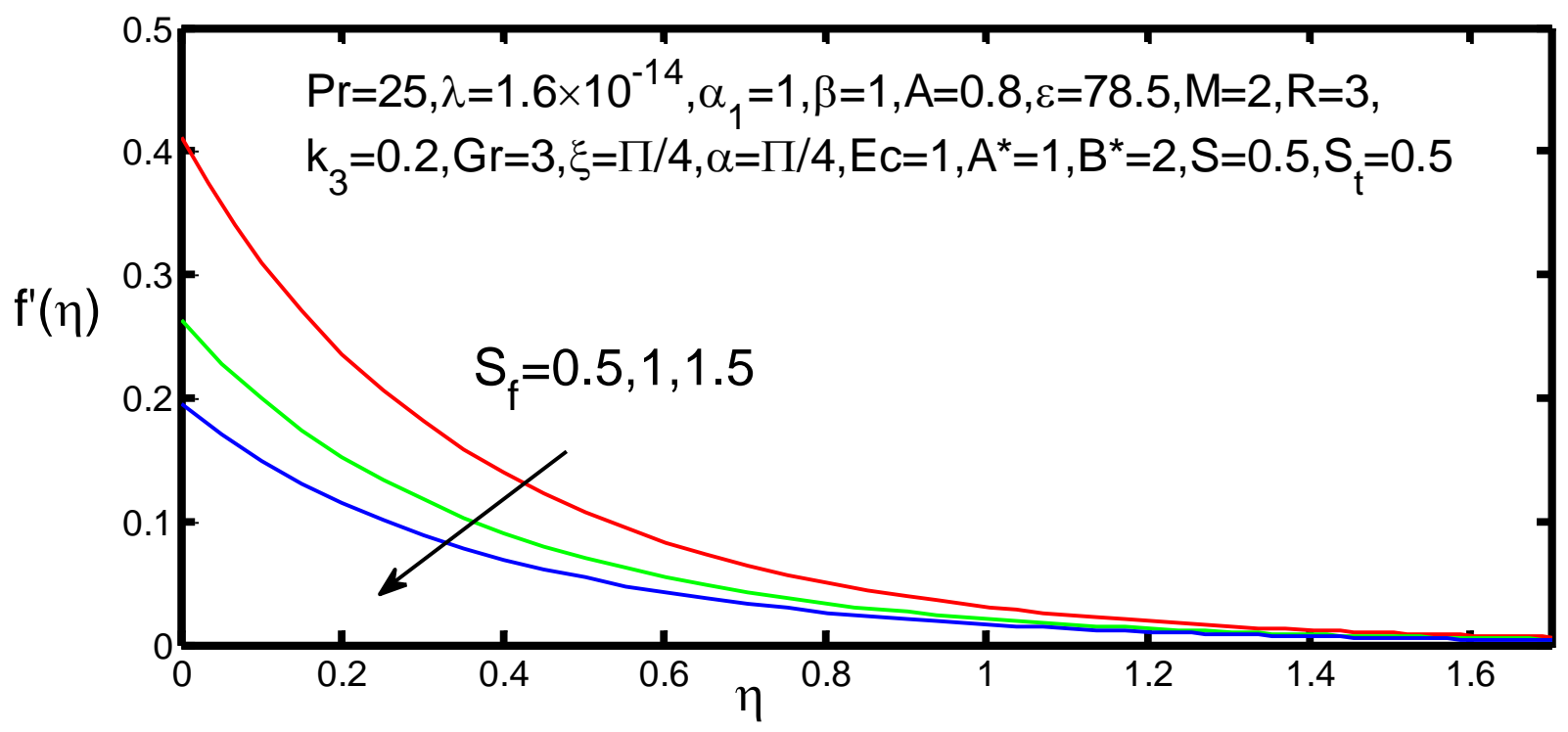

Figure 14. Velocity profile $f^{\prime}(\eta)$ for various values of $S_{f}$.

The effect of the thermal slip parameter $S_{t}$ on the velocity and temperature profiles is shown in Figures 16 and 17. In Figure 16, it can be observed that the presence of the thermal slip factor on the temperature profiles has a significant effect. It is clear that the temperature near the surface is decreased as the values of $S_{t}$ are increased. This is happening because the increment in the thermal slip parameter results in the increment of the thermal coefficient, and the thermal diffusion towards the blood flow is reduced. The reverse behavior takes place for the velocity boundary layer, as shown in Figure 16.

Figures 18 and 19 show the effects of the permeability parameter $k_{3}$ on the velocity and temperature profiles. It is observed from Figure 18 that the presence of permeability parameter $k_{3}$ on the velocity profiles has a significant incremental effect. This is happening because the flow increases over the sheet as the permeability parameter is increased. The resistance on the flow above the sheet is decreased as the permeability of the sheet increases. From Figure 19, it can be noticed that the temperature profile declines when the permeability parameter $k_{3}$ enhances. 


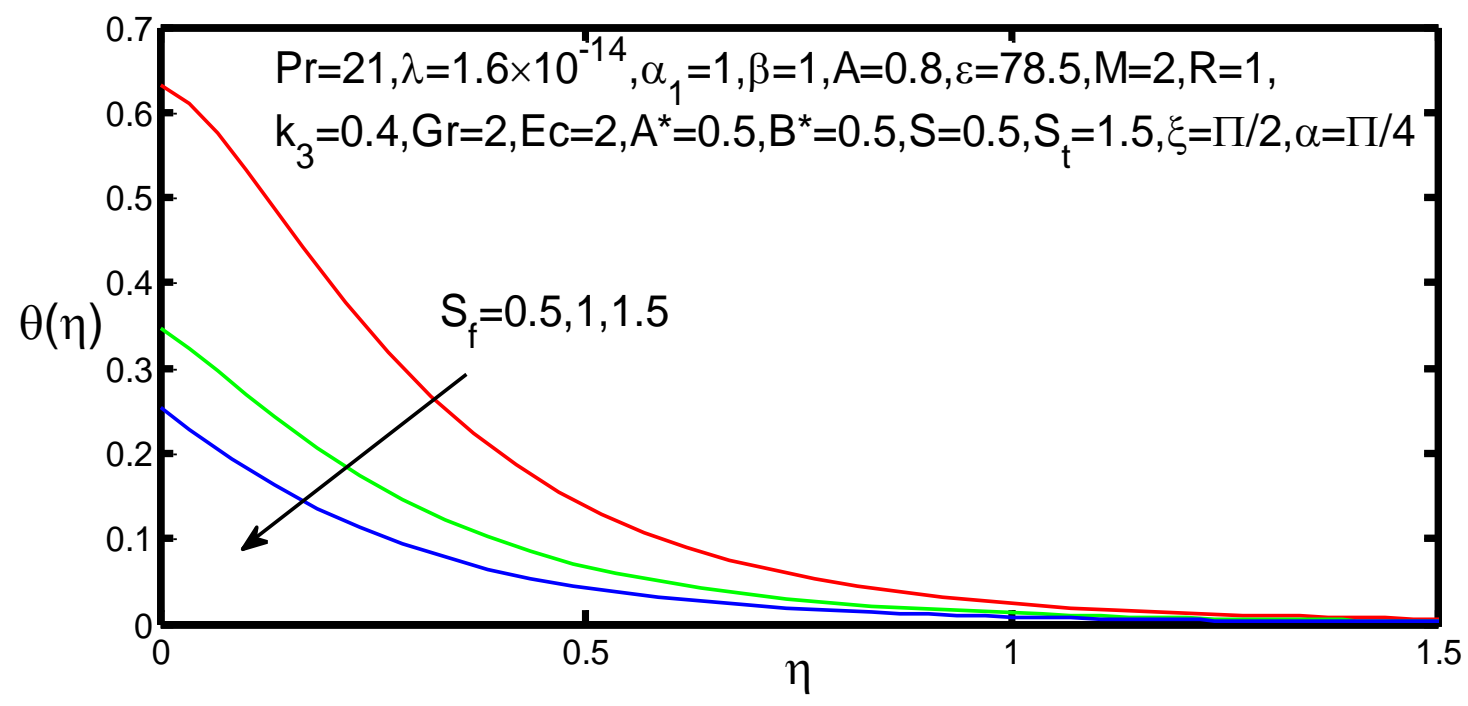

Figure 15. Temperature profile $\theta(\eta)$ for various values of $S_{f}$.

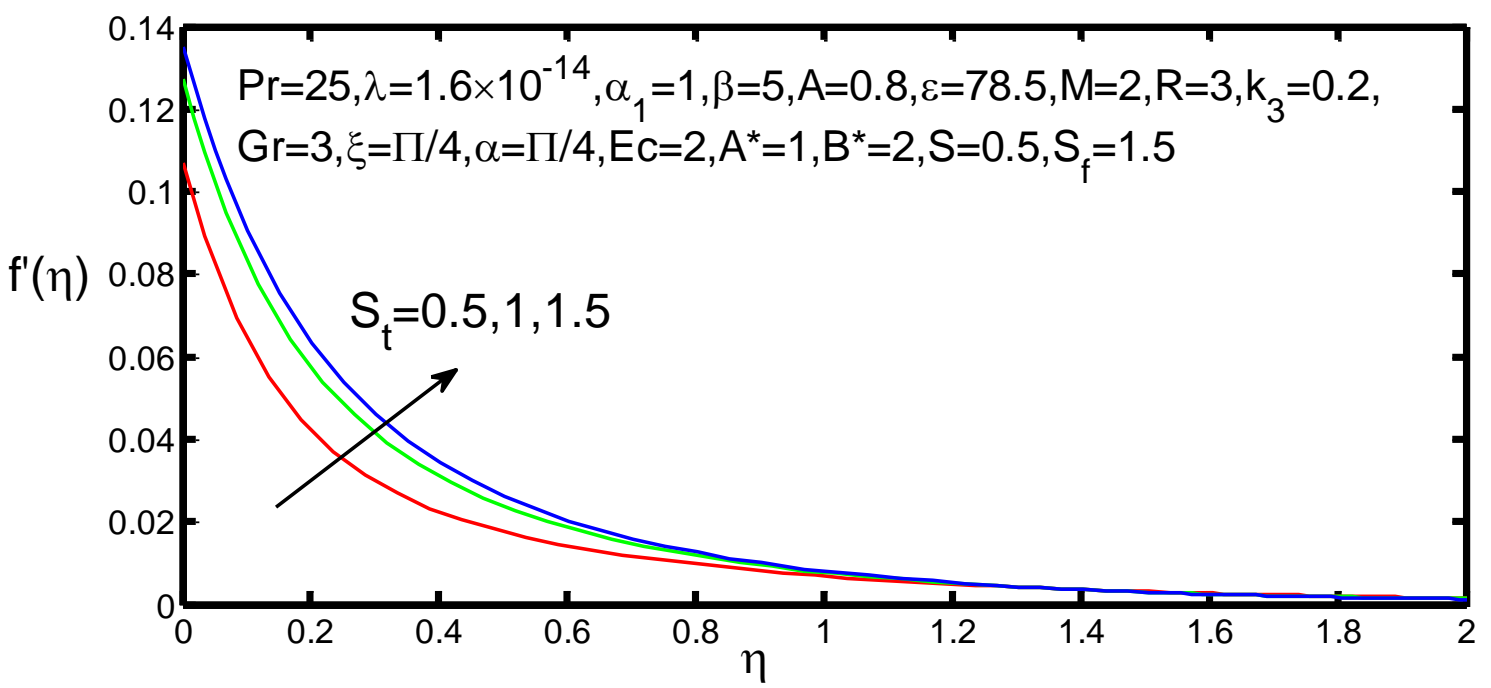

Figure 16. Velocity profile $f^{\prime}(\eta)$ for various values of $S_{t}$.

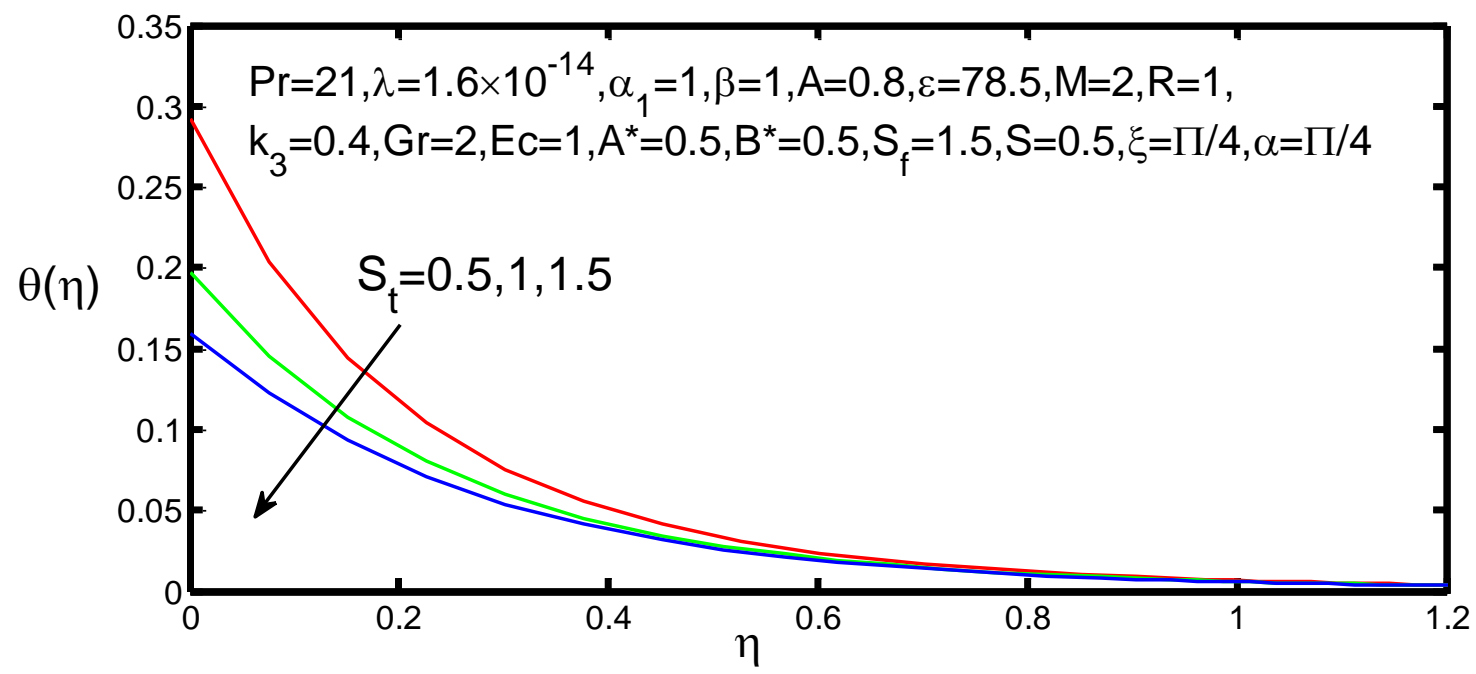

Figure 17. Temperature profile $\theta(\eta)$ for various values of $S_{t}$. 


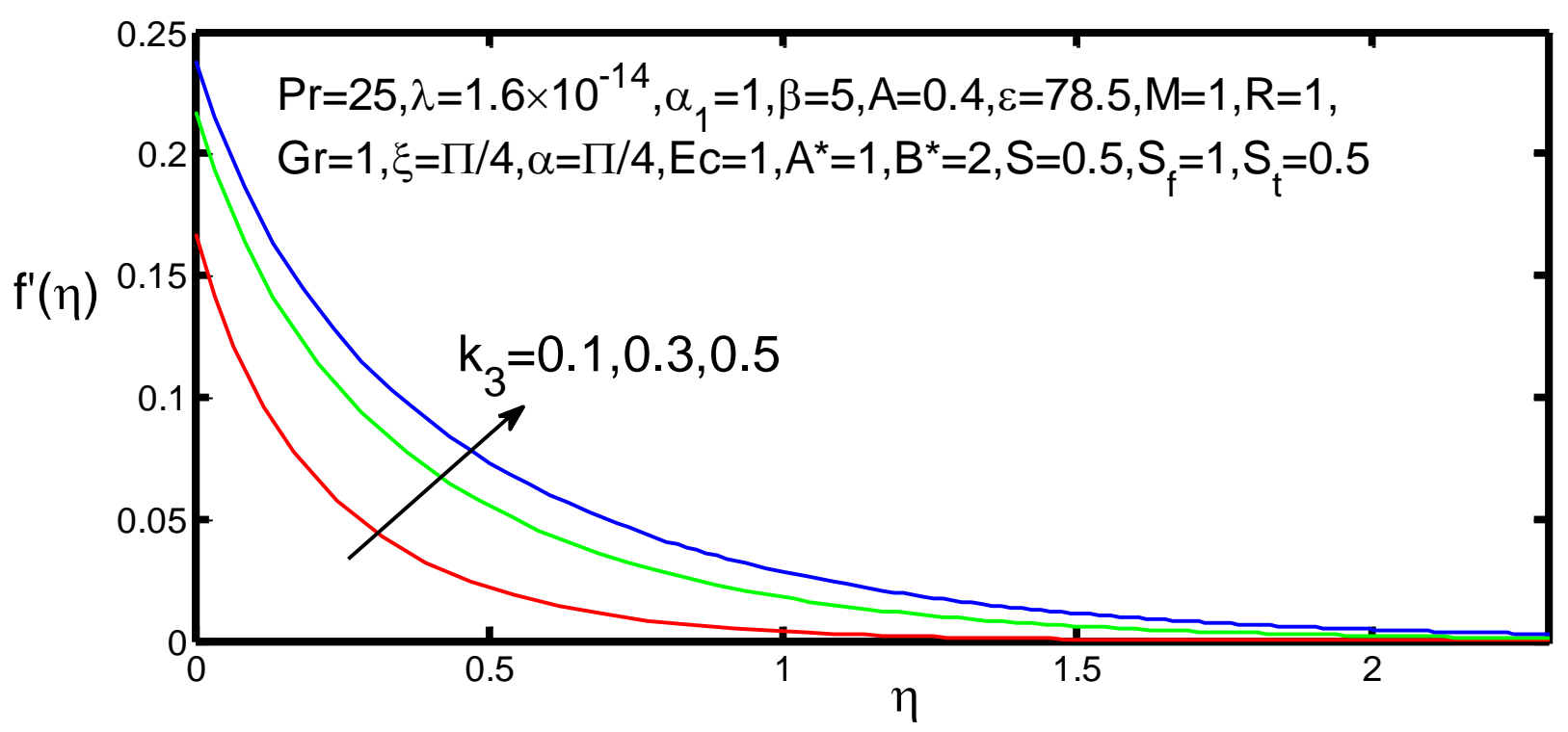

Figure 18. Velocity profile $f^{\prime}(\eta)$ for various values of $k_{3}$.

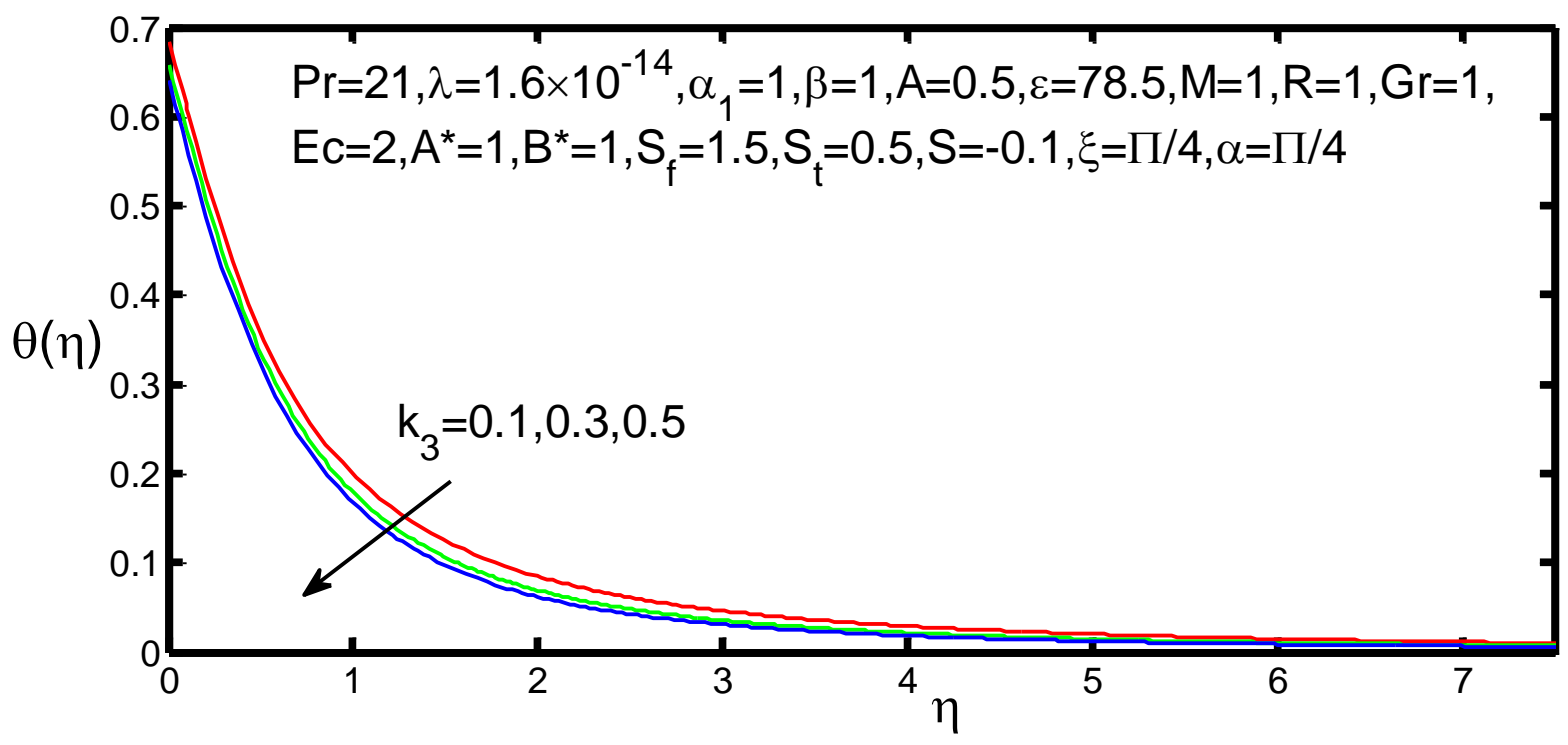

Figure 19. Temperature profile $\theta(\eta)$ for various values of $k_{3}$.

Figures 20 and 21 show the effect of inclination parameter $\alpha$ on the velocity and temperature profiles. From Figure 20, we observe that the velocity profile decreases with an increment in the inclination parameter $\alpha$. It seems that the angle of inclination decreases the effect of the buoyancy force due to thermal diffusion by a factor of $\cos \alpha$. Therefore, the driving force to the fluid decreases, and, as a result, the velocity is finally decreased. The reverse is happening in the temperature profile, which is shown in Figure 21.

Figures 22 and 23 show the effect of the inclination angle of the magnetic field $\xi$ on the velocity and temperature profiles. It is noticed that the velocity profile is reduced and that the temperature profile is enhanced by the increment in the inclination angle. This may be due to the fact that a rise in the aligned angle makes the applied magnetic field stronger.

Figures 24 and 25 depict the effects of the magnetic parameter $M$ on the velocity and temperature profiles. It is observed that the velocity profile is decreased as the magnetic parameter is increased. The increment of the magnetic parameter increases the introduced Lorentz force in the boundary layer, and, hence, the velocity profile in the boundary layer is decreased. An increment in the magnetic parameter would enhance the Lorentz force 
and, consequently, an augmentation of the Lorentz force opposes the flow, and the fluid motion is reduced. From Figure 25, it is noticed that the temperature profiles increase as the magnetic parameter increases. This indicates the fact that the introduction of the transverse magnetic field to an electrically conductive fluid gives rise to the Lorentz force. All these effects result in the increment of the temperature of the fluid.

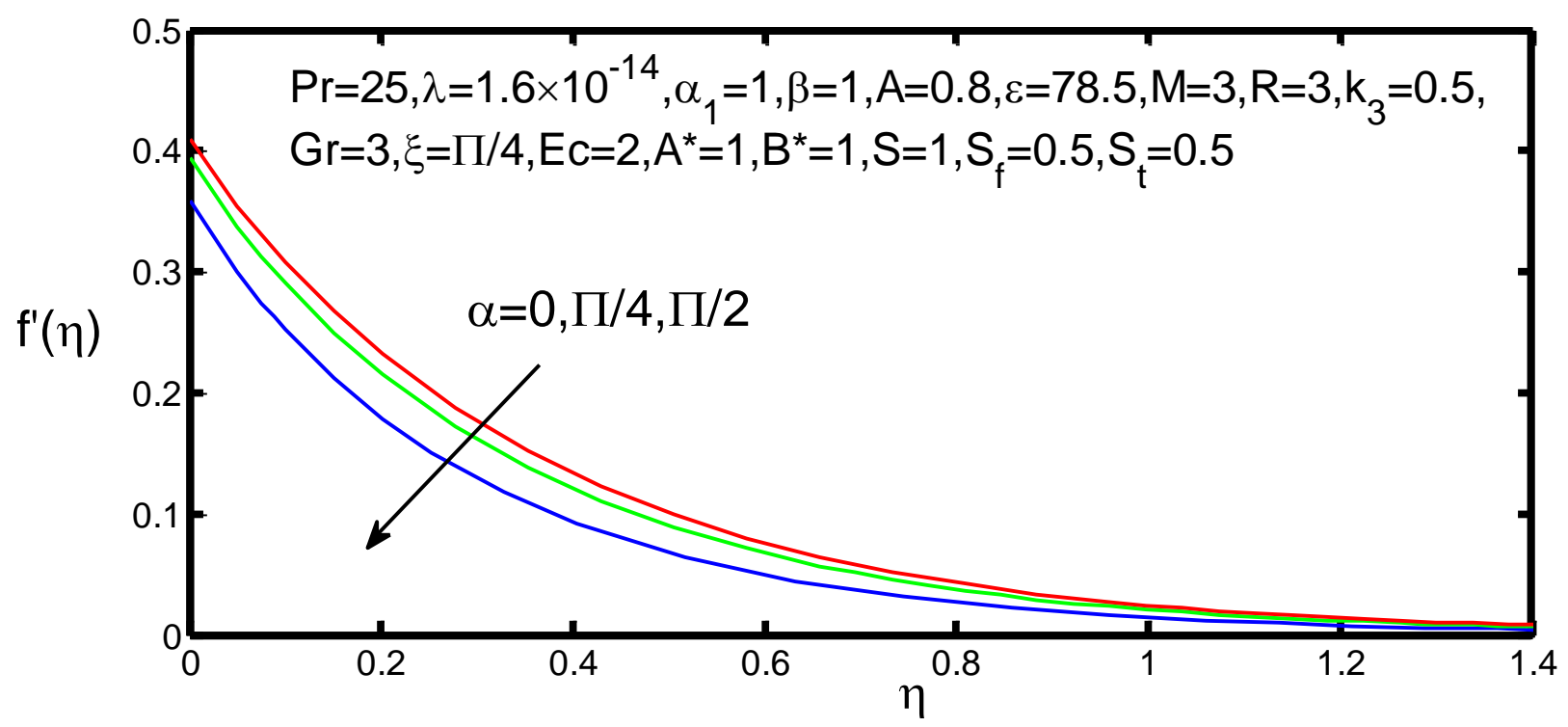

Figure 20. Velocity profile $f^{\prime}(\eta)$ for various values of $\alpha$.

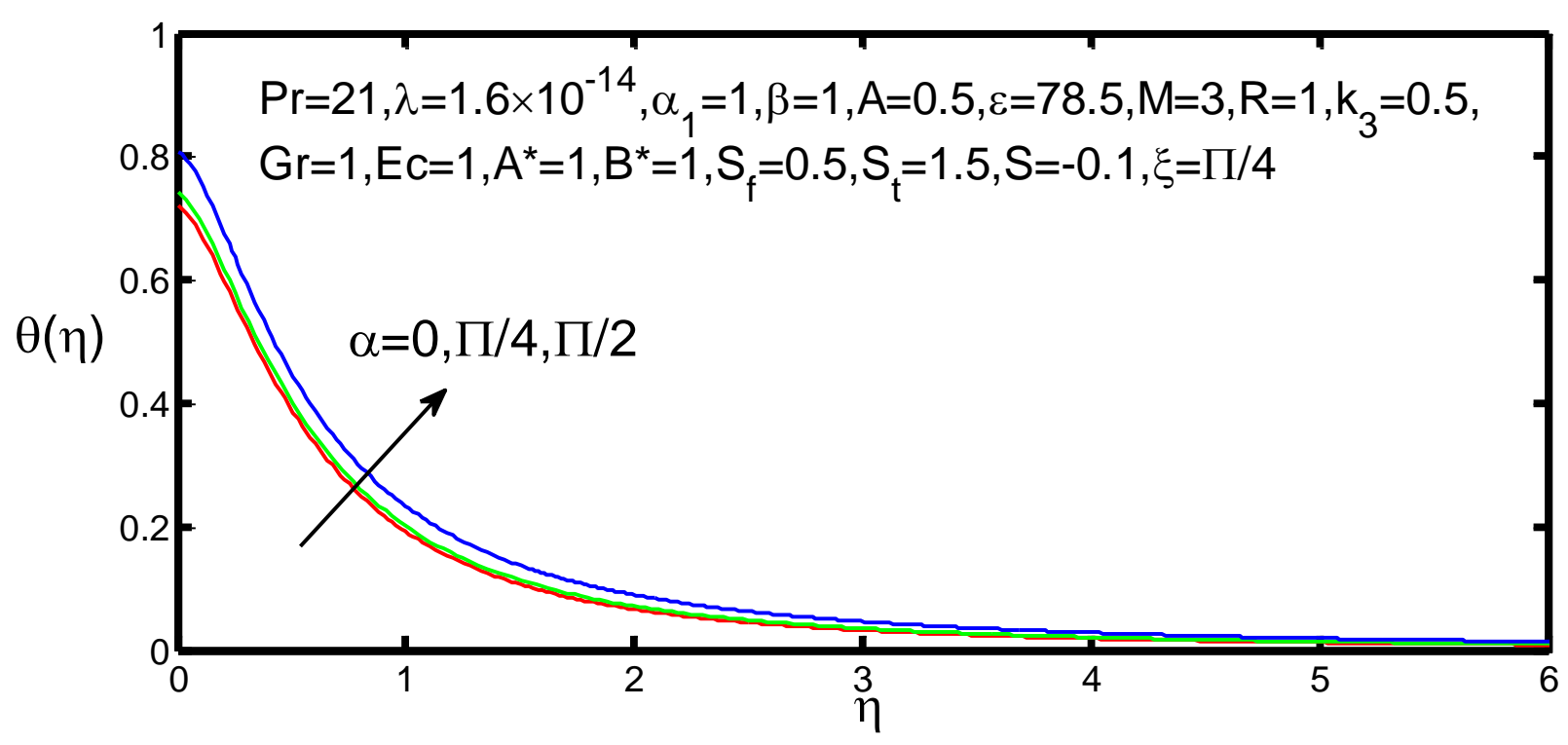

Figure 21. Temperature profile $\theta(\eta)$ for various values of $\alpha$.

The velocity and temperatre profiles for various values of ferromagnetic interaction parameter $\beta$ are shown in Figures 26 and 27. It is observed that the velocity of the fluid decreases with an increment of ferromagnetic number, whereas the temperature profile is increased in these cases. The region behind that ferromagnetic number is directly related to the celvin force, which is also known as the drug force. The results observed in Figures 24-27 are in accordance with those presented in [30,31]. 


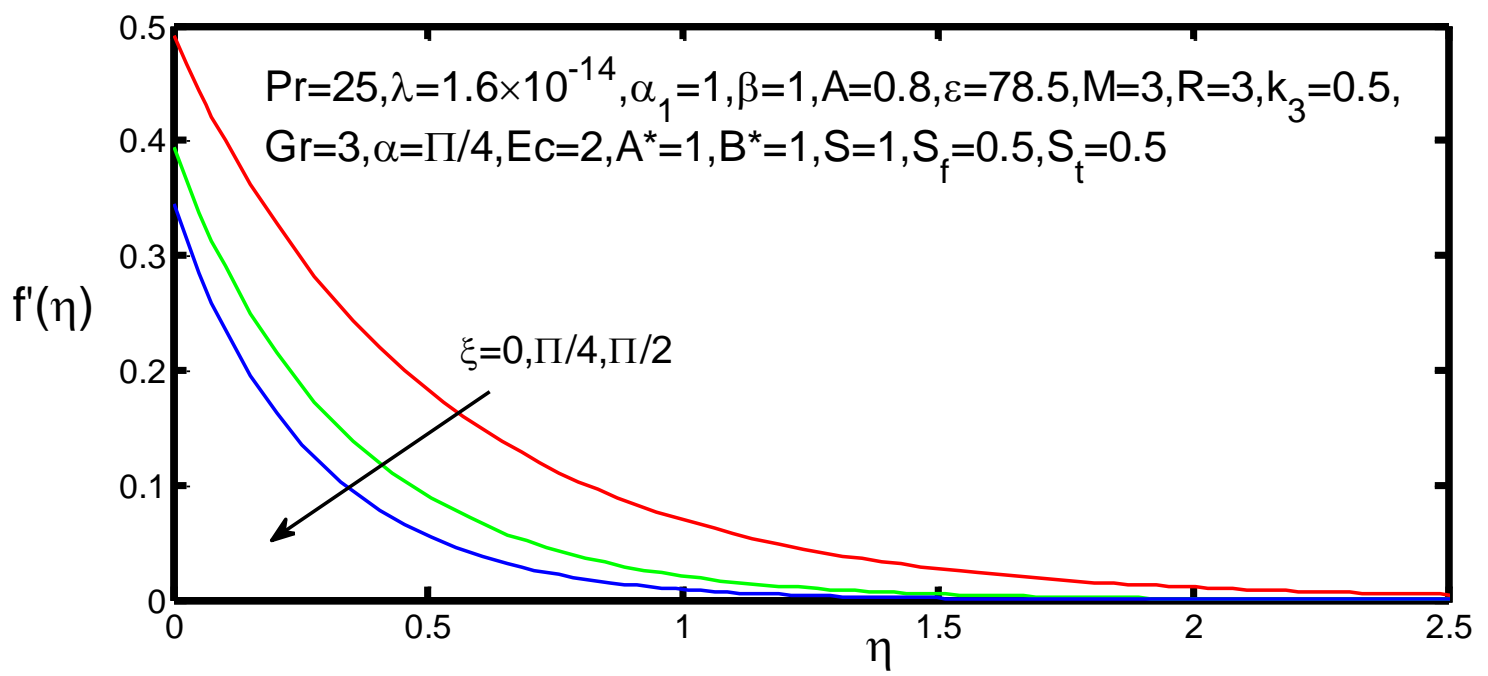

Figure 22. Velocity profile $f^{\prime}(\eta)$ for various values of $\xi$.

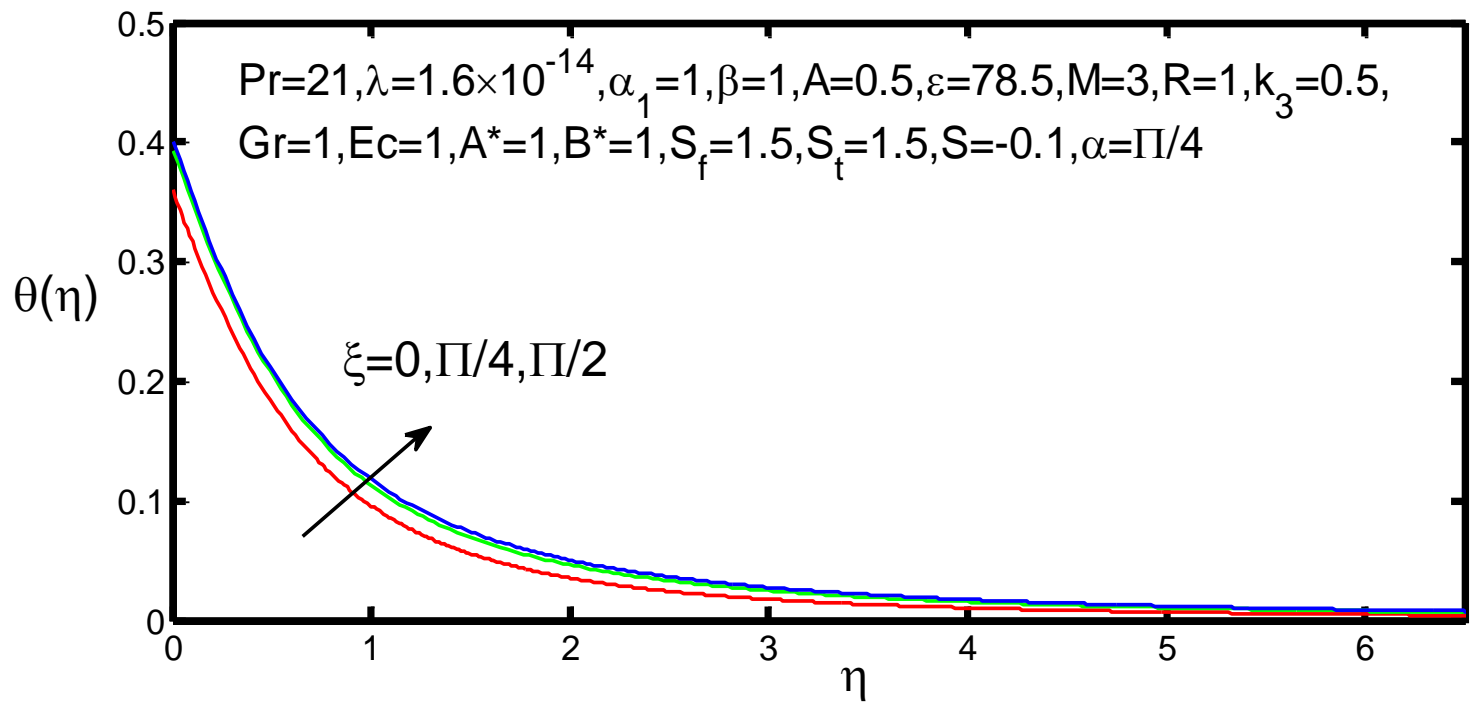

Figure 23. Temperature profile $\theta(\eta)$ for various values of $\xi$.

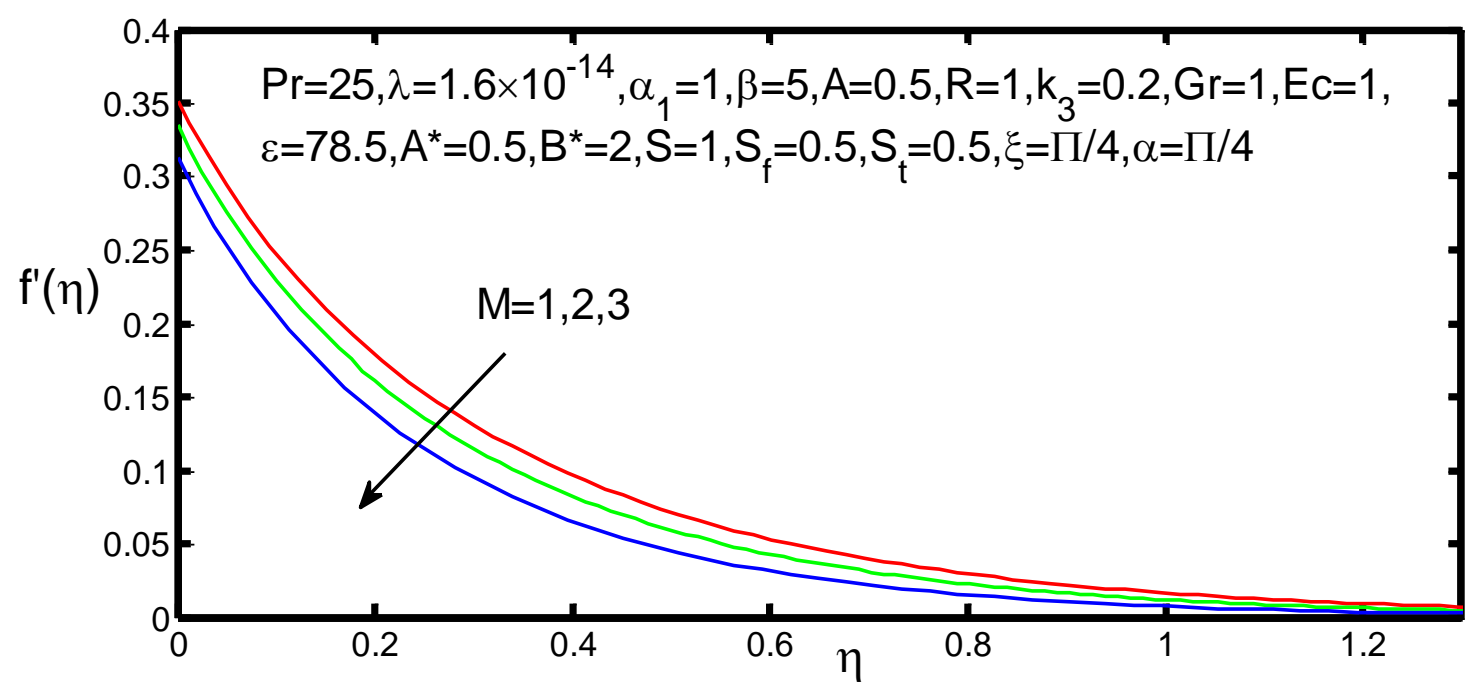

Figure 24. Velocity profile $f^{\prime}(\eta)$ for various values of $M$. 


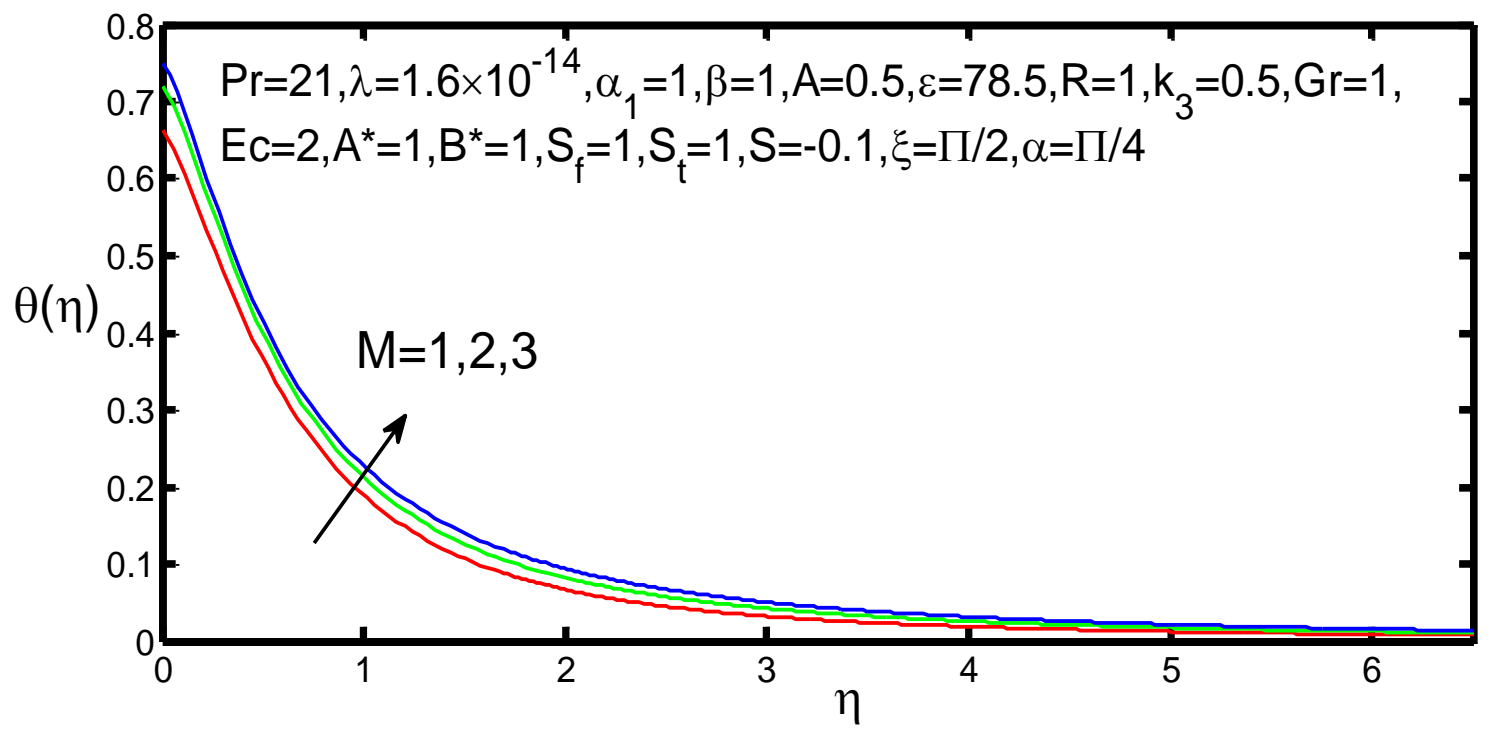

Figure 25. Temperature profile $\theta(\eta)$ for various values of $M$.

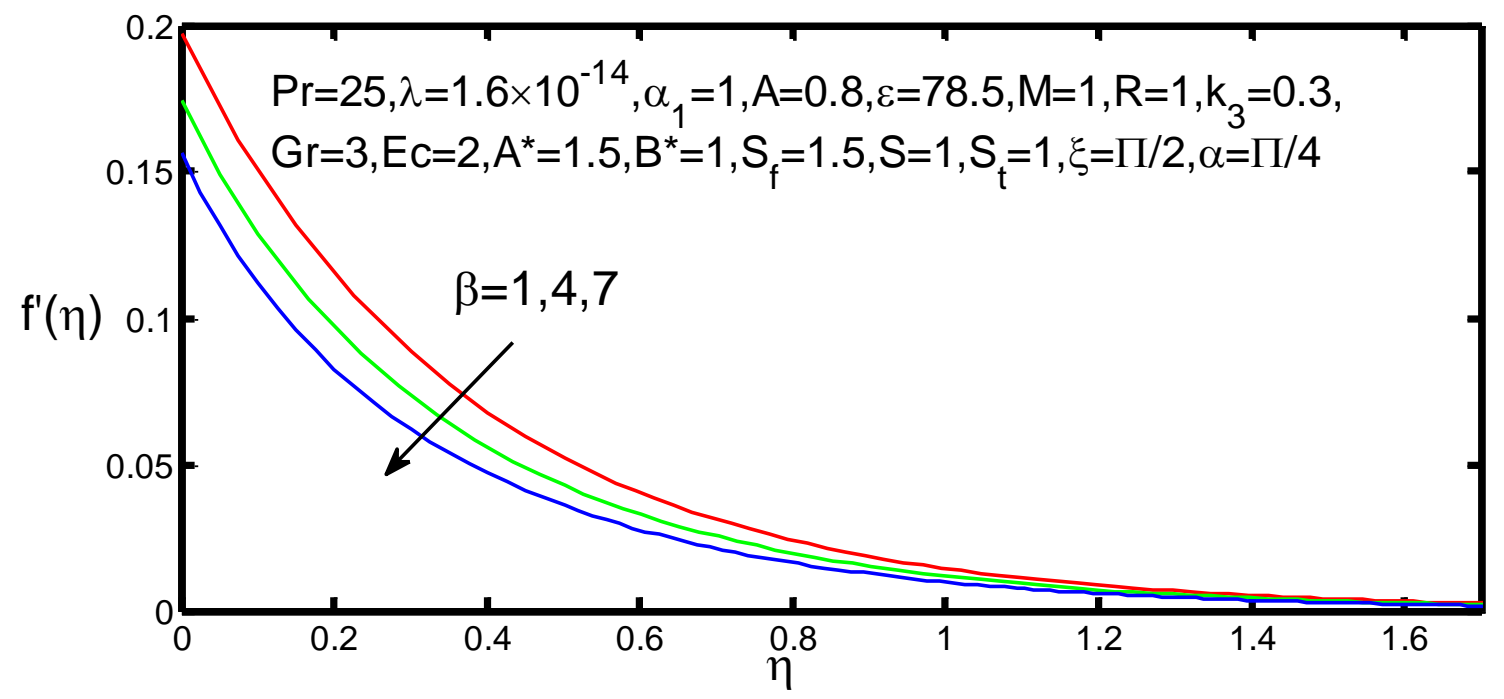

Figure 26. Velocity profile $f^{\prime}(\eta)$ for various values of $\beta$.

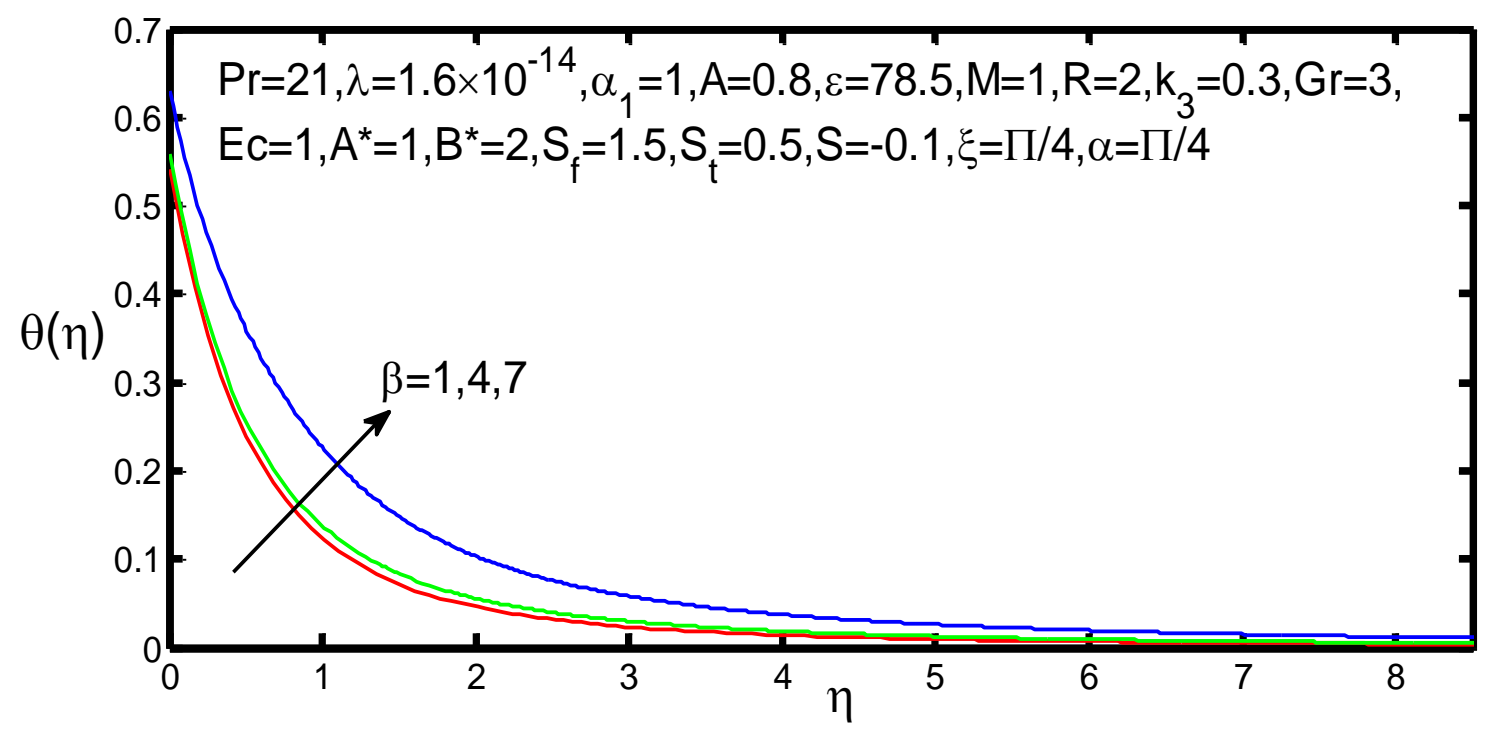

Figure 27. Temperature profile $\theta(\eta)$ for various values of $\beta$. 
Figures 28-39 depict the skin friction coefficient and the rate of wall heat transfer with regard to the magnetic parameter for various values of the inclination angle of the sheet, angle of the magnetic field, radiation parameter, ferromagnetic parameter, unsteadiness parameter, and Eckert number. From the figures, it can be observed that skin friction decreases with increasing values of the inclination angle of the sheet and the acute angle of magnetic field, whereas the rate of the wall heat transfer is increased in these cases. Moreover, both skin friction and the rate of wall heat transfer are decreased with increasing values of the radiation parameter, ferromagnetic parameter, and unsteadiness parameter. Moreover, both skin friction and the rate of wall heat transfer are increased with increasing values of the Eckert number.

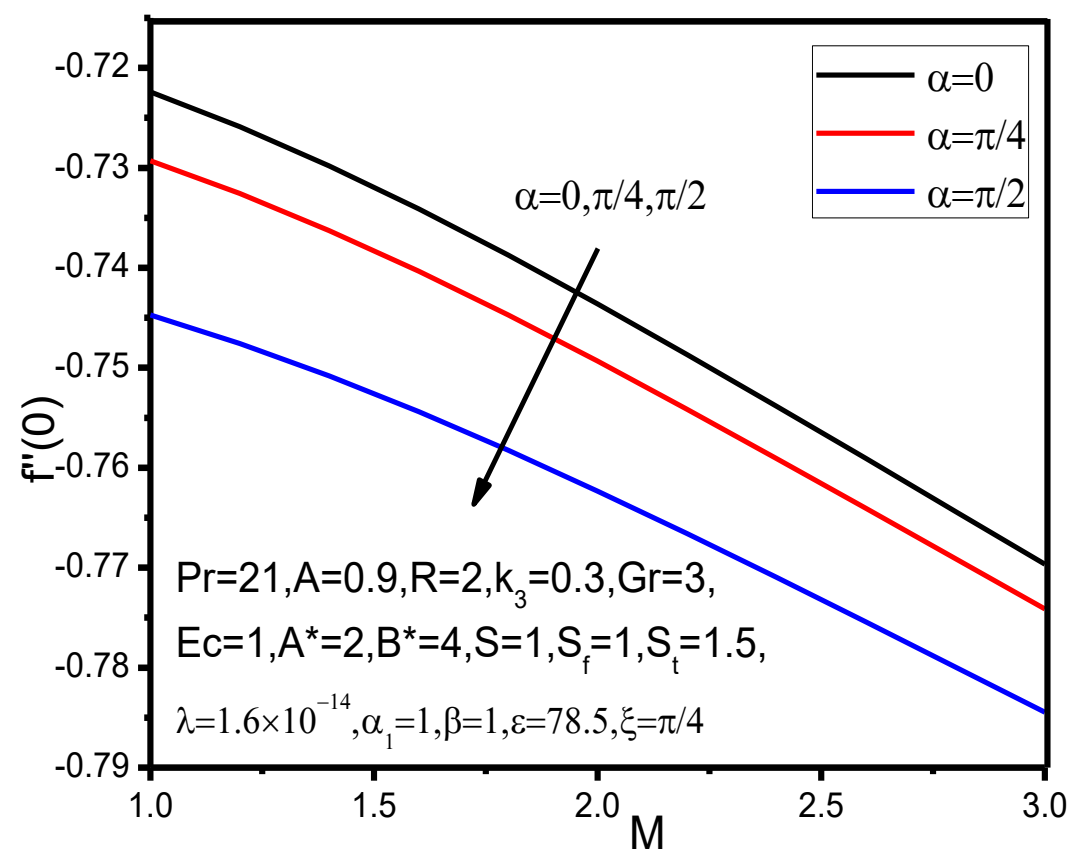

Figure 28. Skin friction coefficient $f^{\prime \prime}(0)$ with $M$ for different values of $\alpha$.

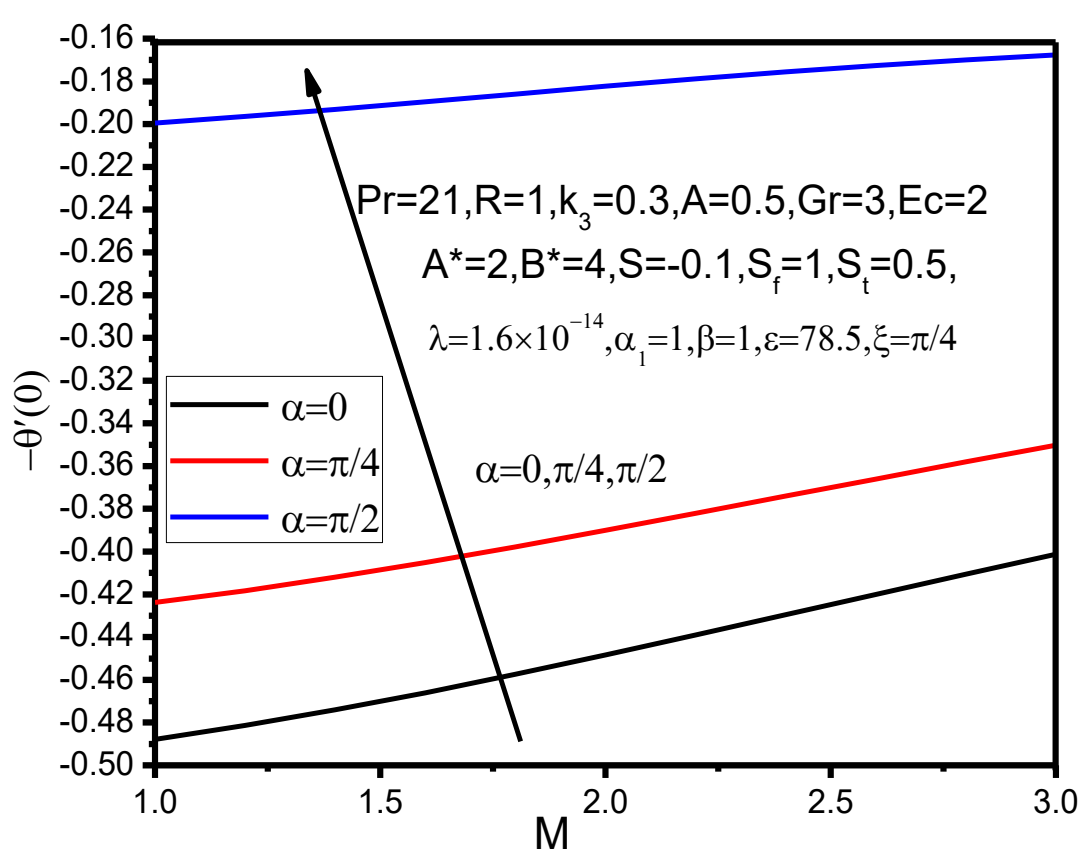

Figure 29. Local Nusselt number $-\theta^{\prime}(0)$ with $M$ for different values of $\alpha$. 


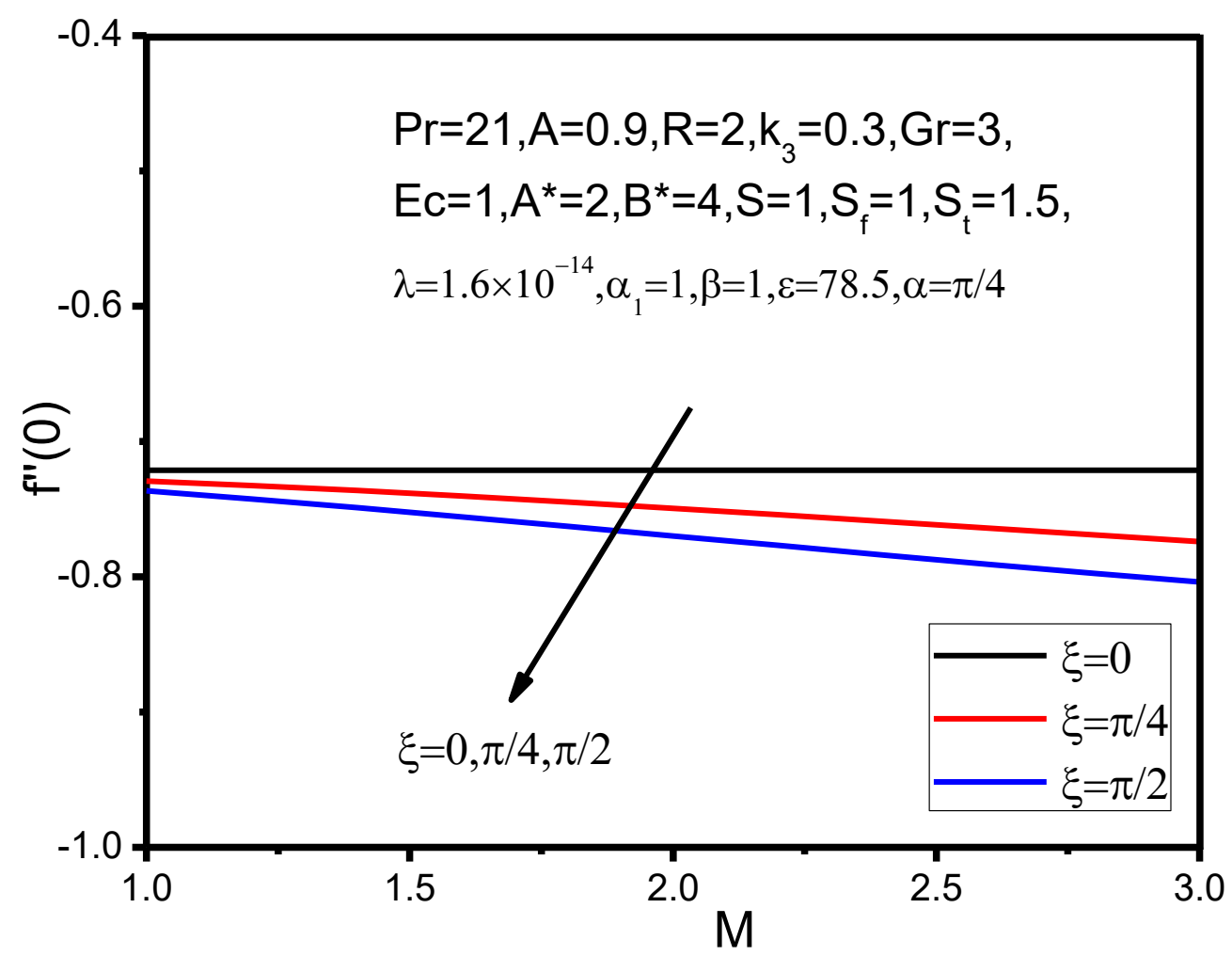

Figure 30. Skin friction coefficient $f^{\prime \prime}(0)$ with $M$ for different values of $\xi$.

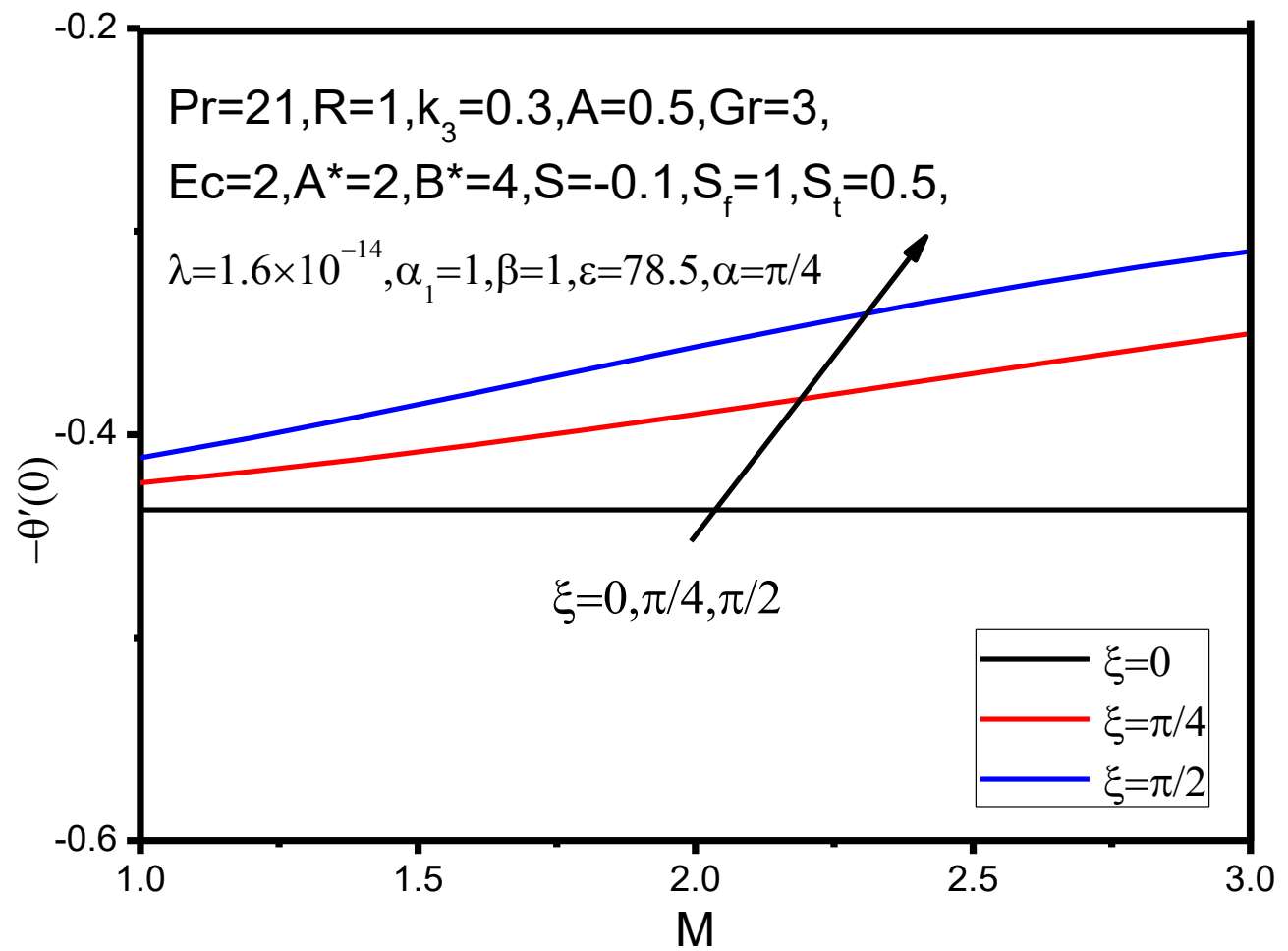

Figure 31. Local Nusselt number $-\theta^{\prime}(0)$ with $M$ for different values of $\xi$. 


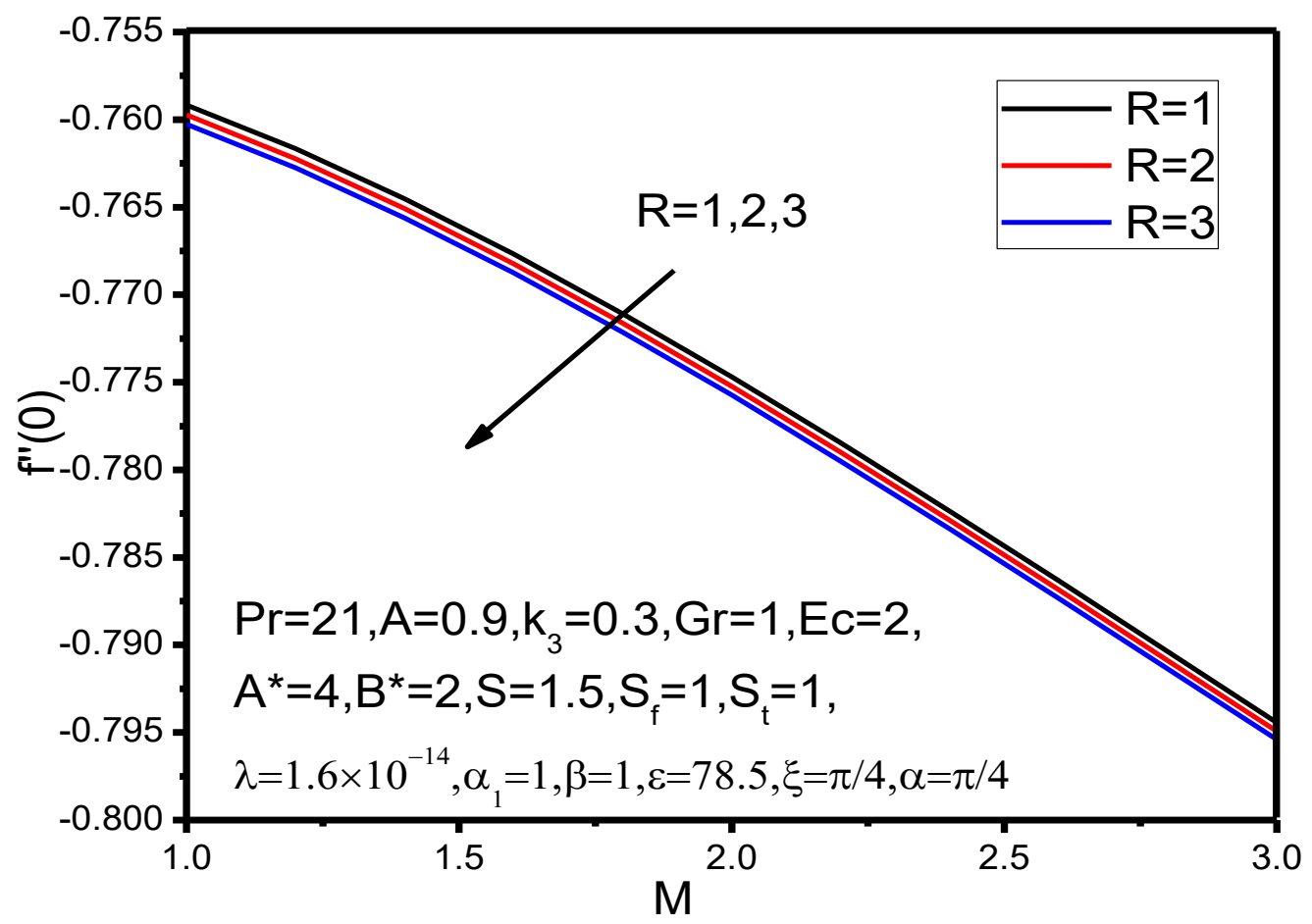

Figure 32. Skin friction coefficient $f^{\prime \prime}(0)$ with $M$ for different values of $R$.

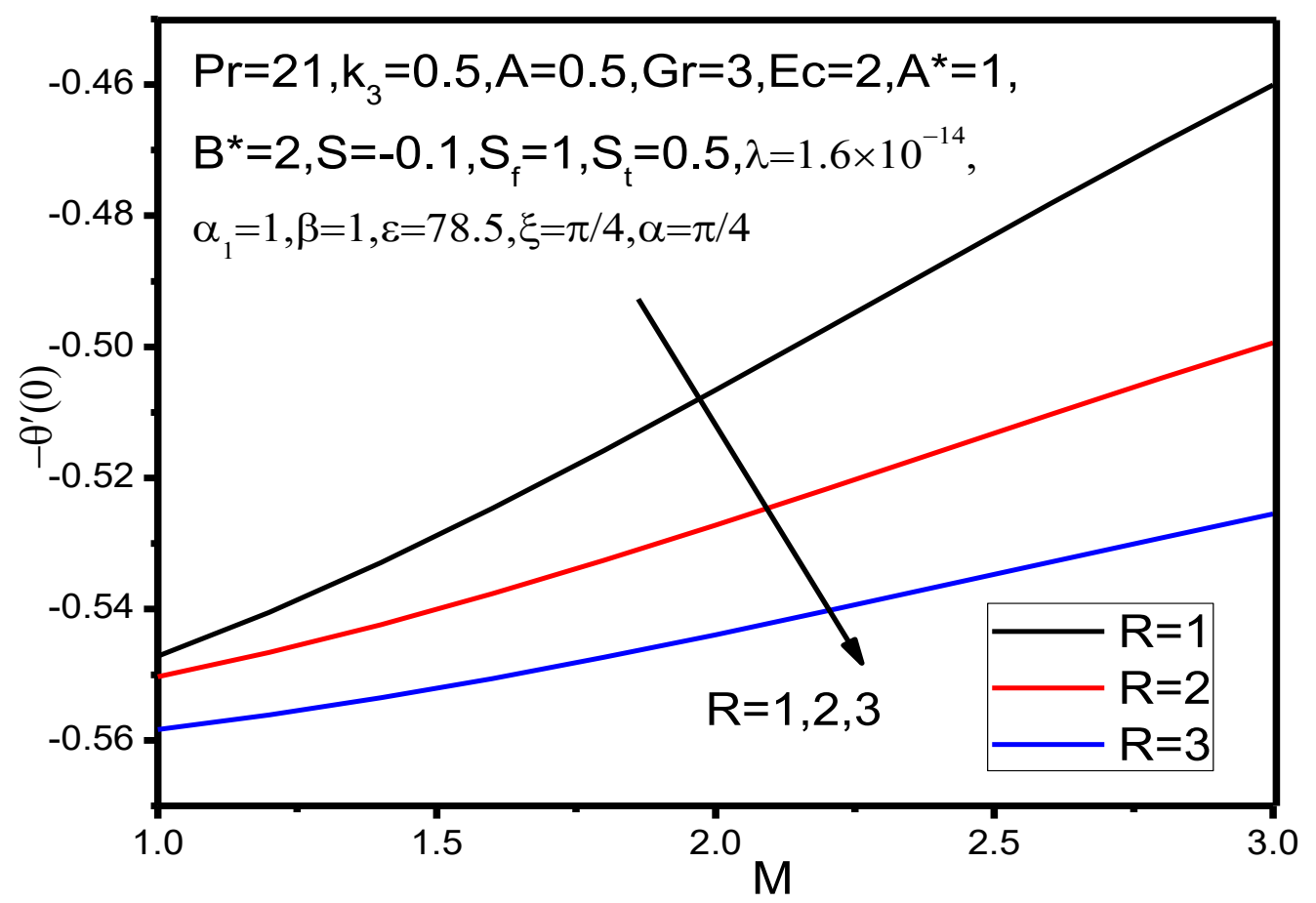

Figure 33. Local Nusselt number $-\theta^{\prime}(0)$ with $M$ for different values of $R$. 


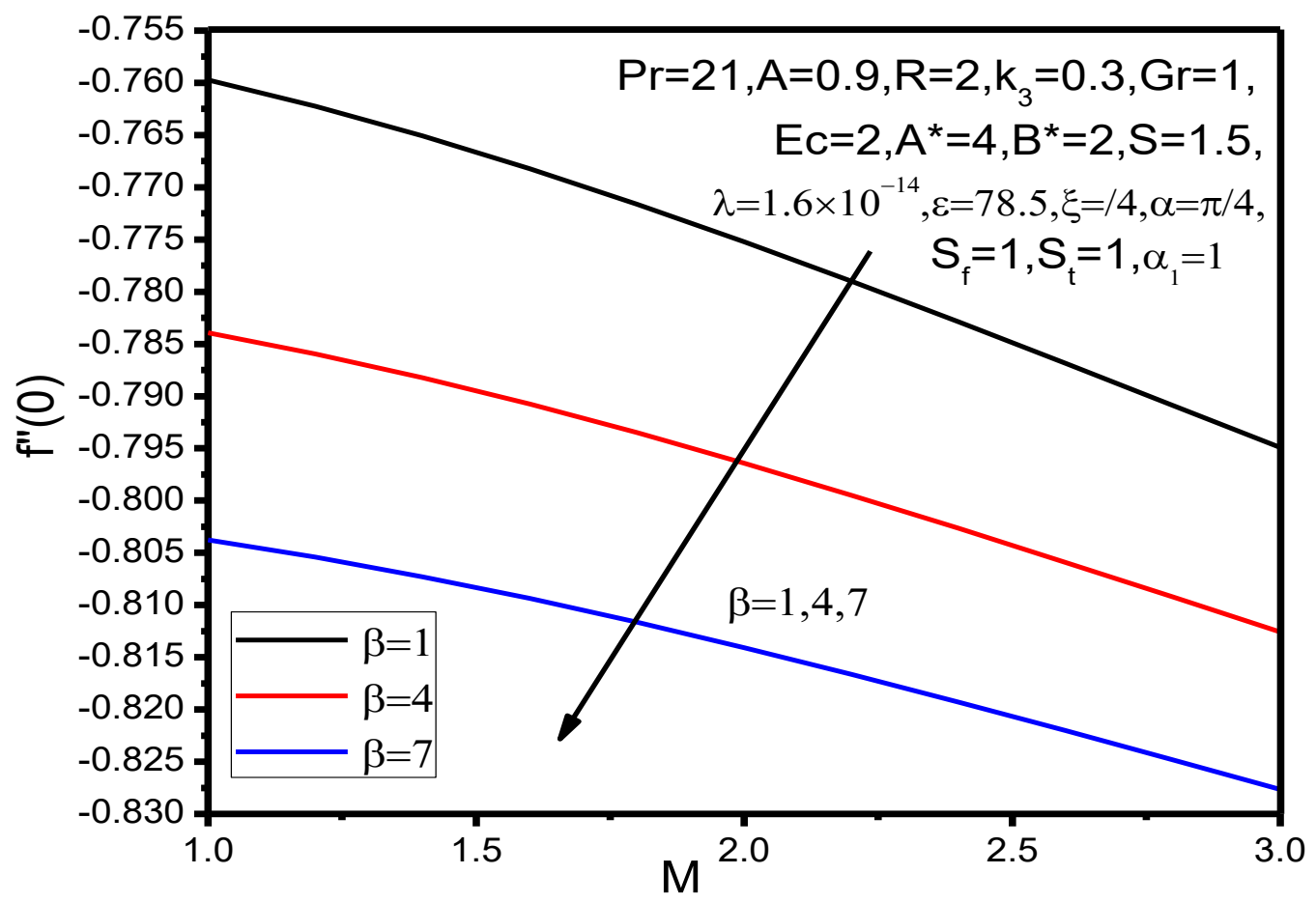

Figure 34. Skin friction coefficient $f^{\prime \prime}(0)$ with $M$ for different values of $\beta$.

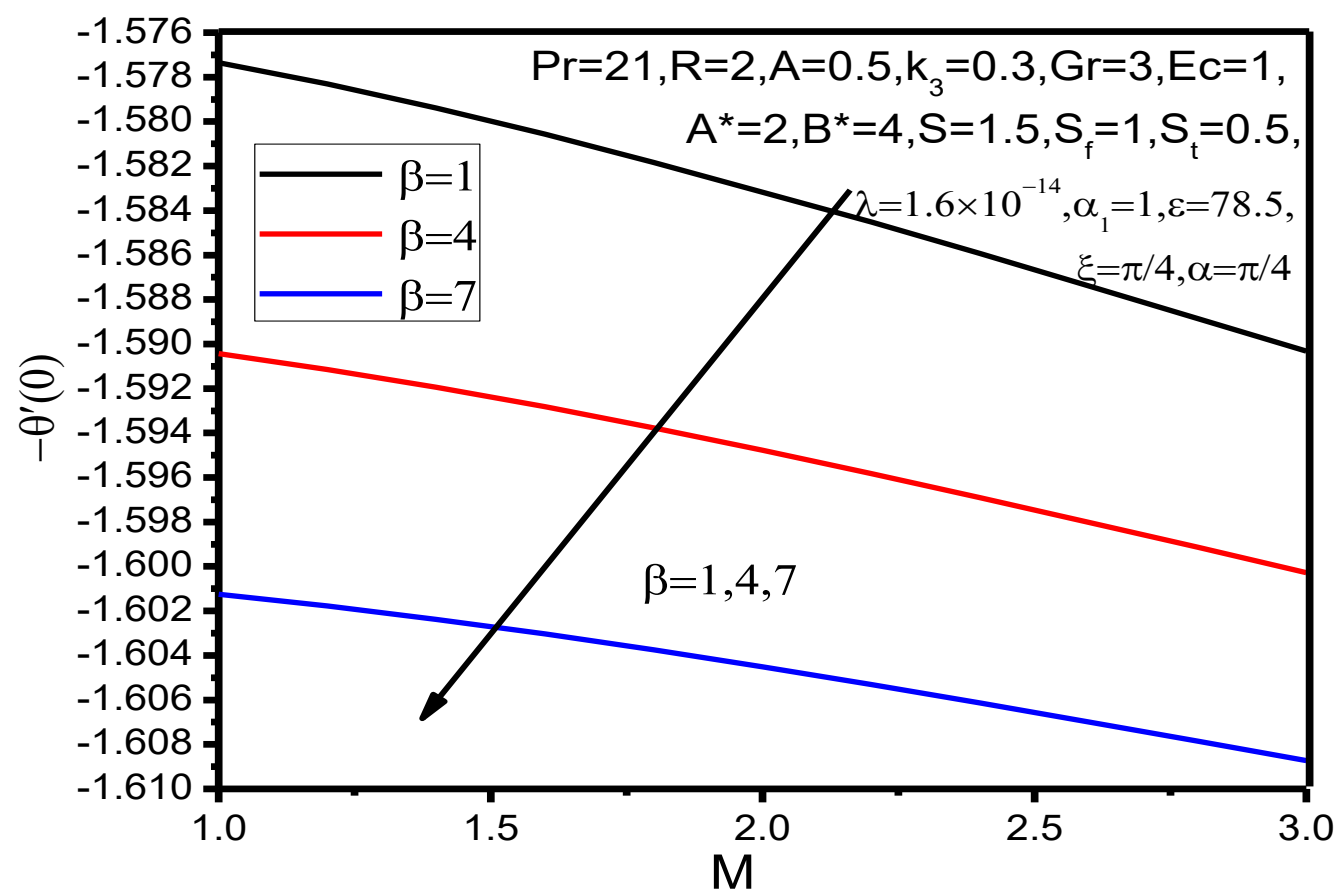

Figure 35. Local Nusselt number $-\theta^{\prime}(0)$ with $M$ for different values of $\beta$. 


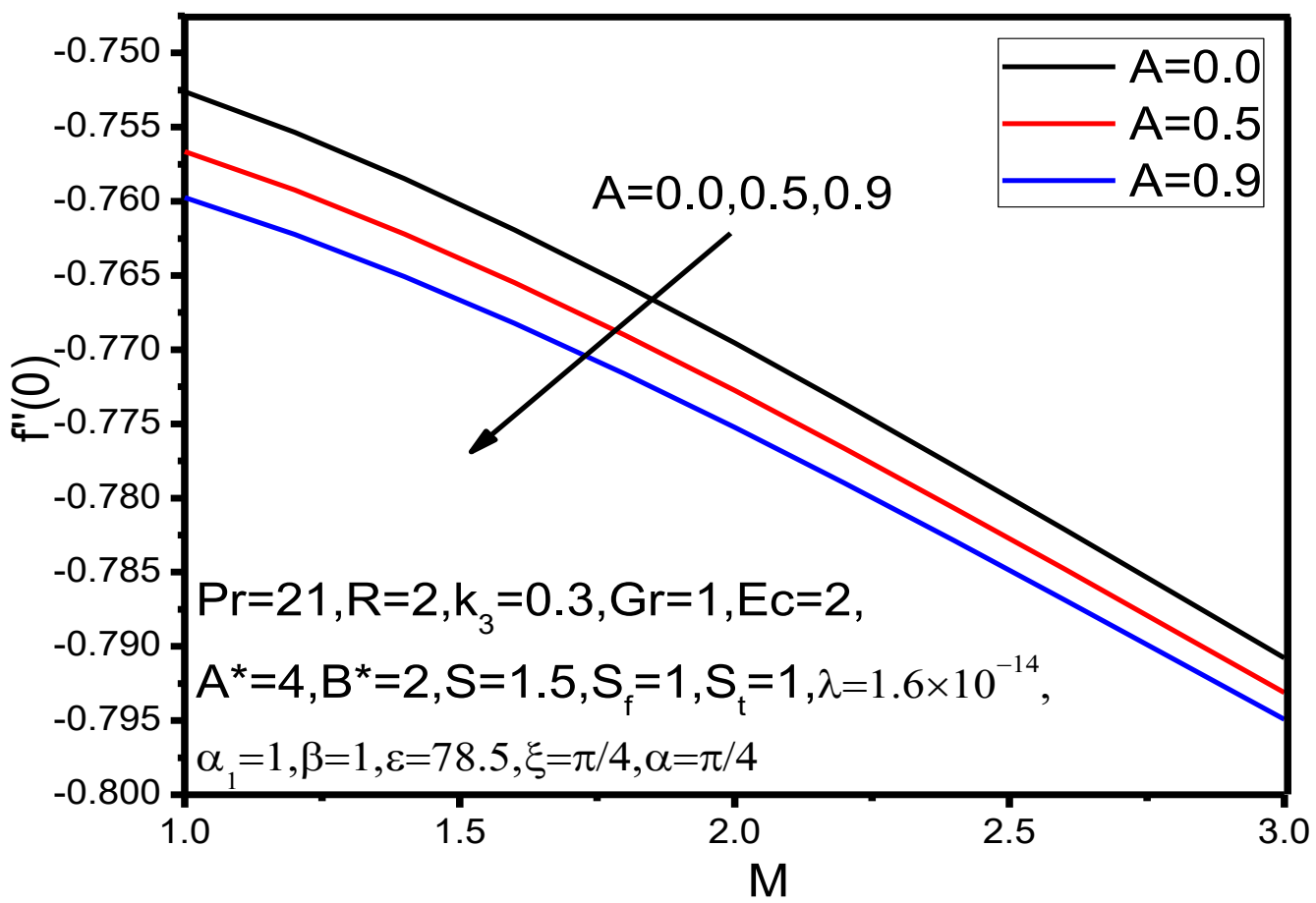

Figure 36. Skin friction coefficient $f^{\prime \prime}(0)$ with $M$ for different values of $A$.

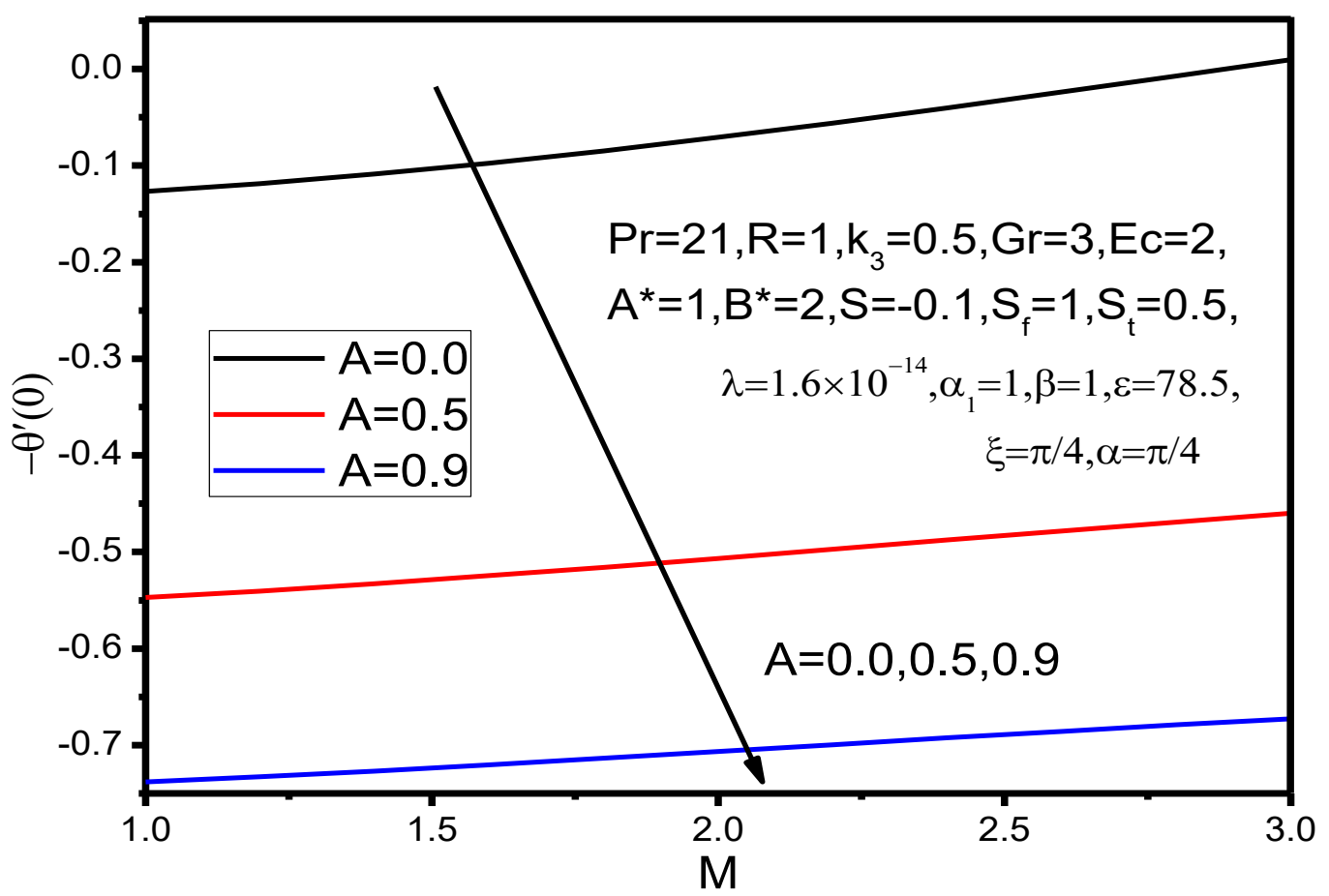

Figure 37. Local Nusselt number $-\theta^{\prime}(0)$ with $M$ for different values of $A$. 


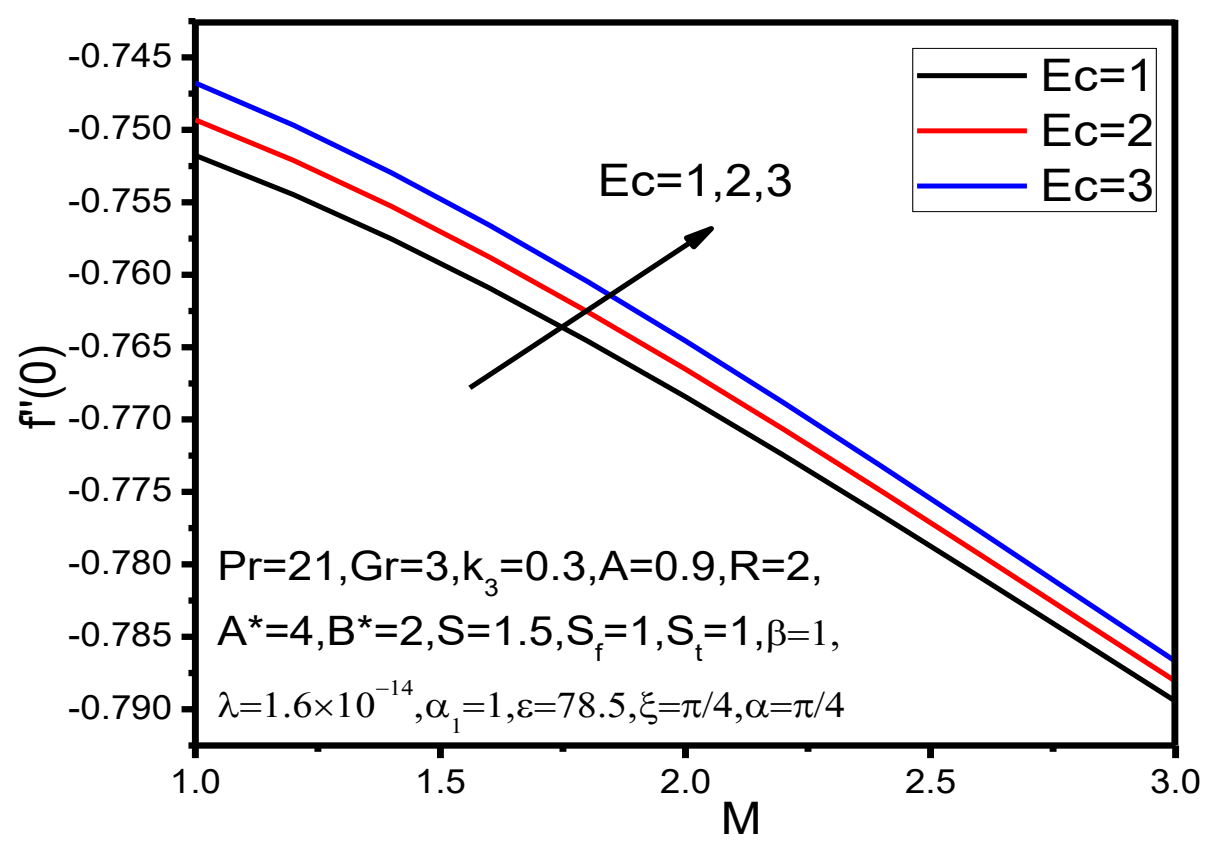

Figure 38. Skin friction coefficient $f^{\prime \prime}(0)$ with $M$ for different values of $E c$.

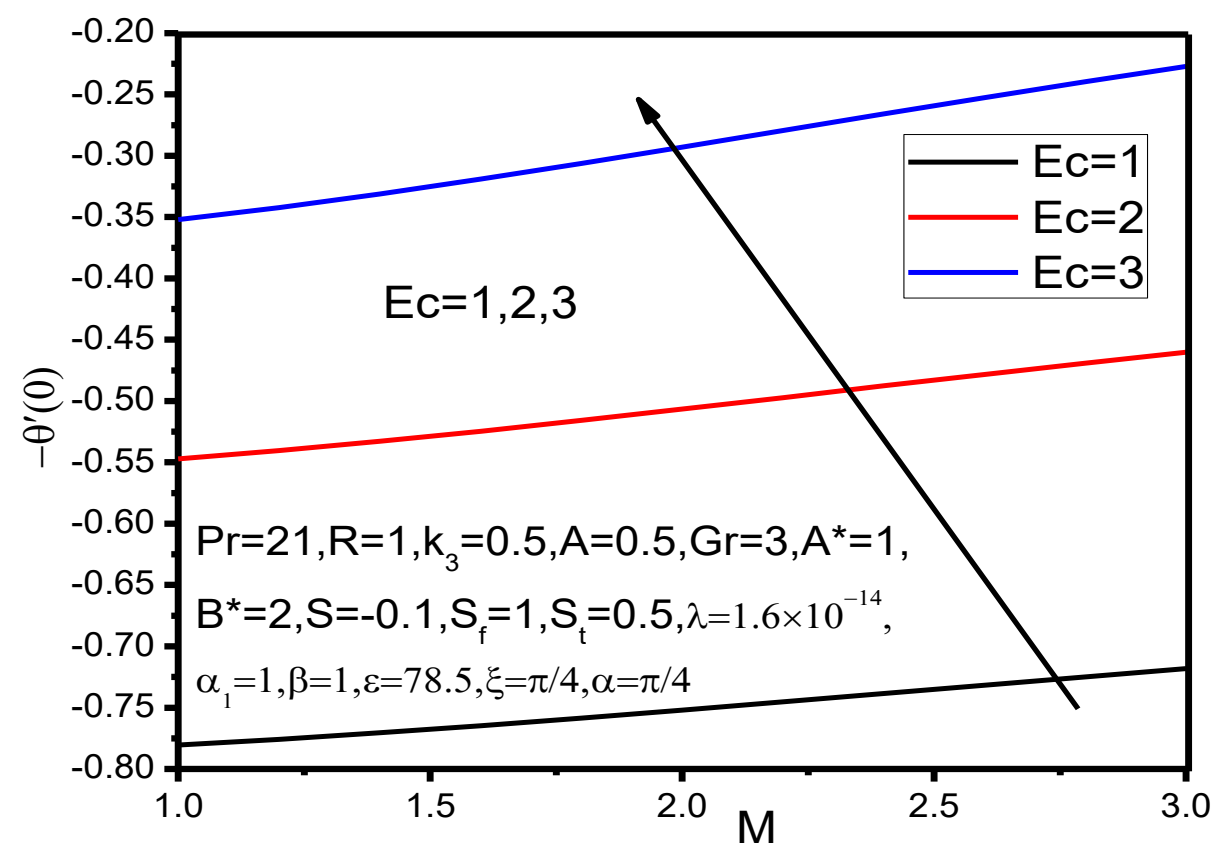

Figure 39. Local Nusselt number $-\theta^{\prime}(0)$ with $M$ for different values of $E c$.

\section{Conclusions}

The results concern the study of the effect of the magnetic field and radiation effects on the two-dimensional unsteady inclined stretching sheet with various slip conditions. We observed that the suction/injection parameter has a good impact on the Nusselt number and skin friction coefficient. Such types of biological fluid flow problems are interesting in the biomedical and bioengineering sectors, especially in drug and gene delivery, cancer treatment, and MRIs. The important findings are given below:

(1) Fluid velocity is reduced with ferromagnetic interaction parameter, radiation parameter, magnetic field parameter, inclination angle of the sheet, and acute angle of magnetic field, whereas the temperature is increased in all cases; 
(2) Fluid velocity is enhanced with Prandtl number, Grashof number, permeability parameter, non-dimensional thermal slip factor, whereas temperature is decreased in all cases;

(3) Both fluid velocity and temperature are decreased with unsteadiness parameter, suction/injection parameter, and non-dimensional velocity slip factor;

(4) Both fluid velocity and temperature are increased with Eckert number, coefficient of space, and a temperature-dependent heat source/sink;

(5) The effects of suction parameter on skin friction are enhanced with the increment of Eckert number, but decreased with an inclination angle of the sheet, acute angle of magnetic field, thermal slip factor, and unsteadiness parameter;

(6) The effects of the injection parameter on the Nusselt number enhanced with the inclination angle of the sheet, acute angle of magnetic field, and Eckert number, but decreased with an increment in the radiation parameter and unsteadiness parameter; (7) In case of suction parameter, both skin friction and Nusselt number are decreased with increasing values of the ferromagnetic interaction parameter.

Author Contributions: Conceptualization, M.F.; Data curation, G.M.; Formal analysis, T.S.; Funding acquisition, G.M.; Investigation, A.G., J.A. and T.S.; Methodology, G.M.; Project administration, M.F.; Resources, A.G. and J.A.; Software, A.G., J.A. and G.M.; Supervision, E.E.T. and M.F.; Validation, G.M., T.S. and M.F.; Writing—original draft, A.G., J.A., G.M. and T.S.; Writing-review \& editing, E.E.T. and M.F. All authors have read and agreed to the published version of the manuscript.

Funding: This research received no external funding.

Data Availability Statement: Not applicable.

Conflicts of Interest: The authors declare no conflict of interest.

\section{References}

1. Tzirtzilakis, E.E. A mathematical model for blood flow in magnetic field. Phys. Fluids 2005, 17, 077103. [CrossRef]

2. Crane, L.J. Flow past a stretching plate. Z. Angew. Phys. 1970, 21, 645-647. [CrossRef]

3. Barozzi, G.S.; Dumas, A.J. Convective Heat Transfer Coefficients in the Circulation. J. Biomech. Eng. 1991, 113, 308-310. [CrossRef]

4. Pennes, H.H. Analysis of tissue and arterial blood temperatures in the resting forearm. J. Appl. Physiol. 1948, 1, 93-122. [CrossRef] [PubMed]

5. Misra, J.C.; Sinha, A.; Shit, G.C. Flow of a Biomagnetic Viscoelastic Fluid: Application to Estimation of Blood Flow in Arteries during Electromagnetic Hyperthermia, a Therapeutic Procedure for Cancer Treatment. Appl. Math. Mech. Engl. Ed. 2010, 31, 1405-1420. [CrossRef]

6. Inoue, S.; Kobaya, M. Biological Activities Caused by Far Infrared Radiation. Int. J. Biometeorol. 1989, 33, 145-150. [CrossRef]

7. Ni, C.; Is, Y.; Kuniasu, K.; Koga, T. Effects of Ultrasonic Radiation on Cutaneous Blood Flow in the Paw of Decerebrated Rats. Kawasaki J. Med. Welf. 2006, 12, 13-18.

8. Bidin, B.; Nazar, R. Numerical Solution of the Boundary Layer Flow over an Exponentially Stretching Sheet with Thermal Radiation. Eur. J. Sci. Res. 2009, 33, 710-717.

9. Rashid, I.; Haq, R.U.; Al-Mdallal, Q.M. Aligned Magnetic Field Effects on Water Based Metallic Nanoparticles over a Stretching Sheet with PST and Thermal Radiation Effects. Phys. E Low-Dimens. Syst. Nanostruct. 2017, 89, 33-42. [CrossRef]

10. Ishak, A. MHD Boundary Layer Flow due to an Exponentially Stretching Sheet with Radiation Effect. Sains Malays. 2011, 40, 391-395.

11. Brinkman, H.C. Heat Effects in Capillary Flow I. Appl. Sci. Res. A 1951, 2, 120-124. [CrossRef]

12. Chand, G.; Jat, R.N. Viscous Dissipation and Radiation Effects on MHD Flow and Heat Transfer over an Unsteady Stretching Surface in a Porous Medium. Thermal. Energy Power Eng. 2014, 3, 266-272.

13. Hassaniean, I.; Essawy, A.; Moursy, N. Variable viscosity and thermal conductivity effects on combined heat and mass transfer in mixed convection over a UHF/UMF wedge in porous media: The entire regime. Appl. Math. Comput. 2003, 145, 667-682. [CrossRef]

14. Khan, Y.; Wu, Q.; Faraz, N. The effects of variable viscosity and thermal conductivity on a thin film flow over shrinking/stretching sheet. Appl. Math. Comput. 2011, 61, 3391-3399. [CrossRef]

15. Pai, D.; Mondal, H. Effects of temperature dependent viscosity and variable thermal conductivity on MHD non-darcy mixed convective diffusion of species over a stretching sheet. J. Egypt. Math. Soc. 2014, 22, 123-133.

16. Bala Anki Reddy, P.; Bhaskar Reddy, N. Radiation effects on MHD combined convection and Mass Transfer flow past a vertical porous plate embedded in a porous medium with Heat generation. Int. J. Appl. Math. Mech. 2010, 6, 33-49. 
17. Nadeem, S.; Zaheer, S.; Fang, T. Effects of thermal radiation on the boundary layer flow of a Jeffery fluid over an exponentially stretching surface. Numer. Algorithms 2011, 57, 187-205. [CrossRef]

18. Bala Anki Reddy, P.; Bhaskar Reddy, N.; Suneetha, S. Radiation effects on MHD flow past an exponentially accelerated Isothermal Vertical plate with uniform Mass diffusion in the presence of Heat Source. J. Appl. Fluid Mech. 2012, 5, 119-126.

19. Khan, A.; Muhammad, S.; Ellahi, R.; Zia, Q.M.Z. Bionic study of variable viscosity on MHD peristaltic flow of pseudo plastic fluid in an asymmetric channel. J. Magn. 2016, 21, 273-280. [CrossRef]

20. Bala Anki Reddy, P.; Bhaskar Reddy, N. MHD boundary layer flow over a vertical permeable stretching cylinder with chemical reaction. Int. J. Sci. Innov. Math. Res. (IJSIMR) 2015, 3, 785-788.

21. Khan, A.A.; Batool, R.; Kousar, N. Examining the behavior of MHD micropolar fluid over curved stretching surface based on the modified Fourier law. Sci. Iran. B 2021, 28, 223-230.

22. Khan, A.A. Peristaltic movement of a dusty fluid in a curved configuration with mass transfer. Punjab Univ. J. Math. 2021, 51, 55-71. [CrossRef]

23. Vijaya, N.; Sreelakshmi, K.; Sarojamma, G. Effect of magnetic field on the flow and heat transfer in a Casson thin film on an unsteady stretching surface in the presence of viscous and internal heating. Open J. Fluid Dyn. 2016, 6, 303-320. [CrossRef]

24. Alam, M.J.; Murtaza, M.G.; Tzirtzilakis, E.E.; Ferdows, M. Effect of thermal radiation on Biomagnetic fluid flow and heat transfer over an unsteady stretching sheet. Comput. Assist. Methods Eng. Sci. (CAMES) 2021, 28, 81-104.

25. Yasim, A.; Ali, K.; Ashraf, M. Study of heat and mass transfer in MHD flow of micropolar Fluid over a curved stretching sheet. Sci. Rep. 2020, 10, 4581.

26. Chamka, A.J.; Aly, A.M.; Mansour, M.A. Similarity Solution for Unsteady Heat and Mass Transfer from a Stretching Surface Embedded in a Porous Medium with Suction/Injection and Chemical Reaction Effects. Chem. Eng. Commun. 2010, 197, 846-858. [CrossRef]

27. Misra, J.C.; Sinha, A. Effect of Thermal Radiation on MHD Flow of Blood and Heat Transfer in a Permeable Capillary in Stretching Motion. Heat Mass Transf. 2013, 49, 617-628. [CrossRef]

28. Brewster, M.Q. Thermal Radiative Transfer and Properties; John Wiley \& Sons: New York, NY, USA, 1992.

29. Tzirtzilakis, E.E. A simple numerical methodology for BFD problems using stream function vortices formulation. Commun. Numer. Methods Eng. 2000, 24, 683-700. [CrossRef]

30. Anderson, H.I.; Valnes, O.A. Flow of a heated Ferro fluid over a stretching sheet in the presence of amagnetic dipole. Acta Mech. 1998, 28, 39-47. [CrossRef]

31. Reddy, S.R.R.; Bala Anki Reddy, P.; Suneetha, S. Magnetohydro dynamic flow of blood in a permeable inclined stretching surface with viscous dissipation, non-uniform heat source/sink and chemical reaction. Front. Heat Mass Transf. (FHMT) 2018, 10, 22.

32. Valvano, J.J.W.; Nho, S.; Anderson, G.T. Analysis of theWeinbaum-Jiji model of blood flow in the canine kidney cortex for self-heated thermistorsrom. J. Biomech. Eng. 1994, 116, 201-207. [CrossRef] [PubMed]

33. Chato, J.J.C. Heat transfer to blood vessels. J. Biomech. Eng. 1980, 102, 110-118. [CrossRef]

34. Vajravelu, K.; Prasad, K.V.; Ng, C.O. Unsteady convective boundary layer flow of a viscous fluid at a vertical surface with variable fluid properties. Nonlinear Anal. Real World Appl. 2013, 14, 455-464. [CrossRef]

35. Magyari, E.; Keller, B. Heat and mass transfer in the boundary layers on an exponentially stretching continuous surface. J. Phys. D Appl. Phys. 1999, 32, 577-585. [CrossRef]

36. El-Aziz, M.A. Viscous dissipation effect on mixed convection flow of a micropolar fluid over an exponentially stretching sheet. Can. J. Phys. 2009, 87, 359-368. [CrossRef]

37. Tzirtzilakis, E.E.; Kafoussias, N.G. Biomagnetic fluid flow over a stretching sheet with nonlinear temperature dependent magnetization. Z. Angew. Math. Phys. (ZAMP) 2003, 8, 54-65.

38. Murtaza, M.G.; Tzirtzilakis, E.E.; Ferdows, M. Effect of electrical conductivity and magnetization on the biomagnetic fluid flow over a stretching sheet. Z. Angew. Math. Phys. (ZAMP) 2007, 68, 93. [CrossRef] 